San Jose State University

SJSU ScholarWorks

Dissertations

Master's Theses and Graduate Research

Spring 2021

\title{
The Effects of Academic Performance, Demographic \\ Characteristics, Work, and Personal Experiences on Admissions to a Clinical Laboratory Science Training Program
}

Mara Williams

San Jose State University

Follow this and additional works at: https://scholarworks.sjsu.edu/etd_dissertations

\section{Recommended Citation}

Williams, Mara, "The Effects of Academic Performance, Demographic Characteristics, Work, and Personal Experiences on Admissions to a Clinical Laboratory Science Training Program" (2021). Dissertations. 53. DOI: https://doi.org/10.31979/etd.cr87-83ew

https://scholarworks.sjsu.edu/etd_dissertations/53

This Dissertation is brought to you for free and open access by the Master's Theses and Graduate Research at SJSU ScholarWorks. It has been accepted for inclusion in Dissertations by an authorized administrator of SJSU ScholarWorks. For more information, please contact scholarworks@sjsu.edu. 
THE EFFECTS OF ACADEMIC PERFORMANCE, DEMOGRAPHIC CHARACTERISTICS, WORK, AND PERSONAL EXPERIENCES ON ADMISSIONS TO A CLINICAL LABORATORY SCIENCE TRAINING PROGRAM

\author{
A Dissertation \\ Presented to \\ The Faculty of the Educational Doctoral Program in Educational Leadership \\ San José State University \\ In Partial Fulfillment \\ of the Requirements for the Degree \\ Doctor of Education
}

by

Mara Williams M.S. MT(ASCP) MB(ASCP) ${ }^{\mathrm{CM}}$

May 2021 
(C) 2021

Mara Williams

ALL RIGHTS RESERVED 
The Designated Dissertation Committee Approves the Dissertation Titled

THE EFFECTS OF ACADEMIC PERFORMANCE, DEMOGRAPHIC CHARACTERISTICS, WORK, AND PERSONAL EXPERIENCES ON ADMISSIONS TO A CLINICAL LABORATORY SCIENCE TRAINING PROGRAM

\author{
by \\ Mara Williams M.S. MT(ASCP) MB(ASCP) CM \\ APPROVED FOR THE EDUCATIONAL DOCTORAL PROGRAM IN \\ EDUCATIONAL LEADERSHIP
}

SAN JOSÉ STATE UNIVERSITY

May 2021

Grinell Smith Ph.D.

Department of Teacher Education

Colette Rabin Ed.D.

Department of Teacher Education

Suzanne Campbell Ph.D. MLS(ASCP) CM

Dean, School of Allied Health

Seward County Community College 


\title{
ABSTRACT \\ THE EFFECTS OF ACADEMIC PERFORMANCE, DEMOGRAPHIC CHARACTERISTICS, WORK, AND PERSONAL EXPERIENCES ON ADMISSIONS TO A CLINICAL LABORATORY SCIENCE TRAINING PROGRAM
}

\author{
by Mara Williams
}

In this study, I sought to discover factors that contributed to candidate success in gaining admission to the San Jose State University Clinical Laboratory Scientist (CLS) Training Program. Social Cognitive Career Theory suggests that the interplay between an individual's personal characteristics and life experiences lead to self-efficacy expectations, learning experiences, and goal setting which crystalizes their choice of career. To understand these phenomena in the context of CLS candidates, I used quantitative methods to explore the influence of race, gender, age, work, and personal experience on the probability of a candidate gaining an interview or placing for clinical internship in the CLS program and qualitative methods to interrogate the process applicants engaged in during their preparation for admission. Successful candidates often developed their interest in laboratory careers through direct experience in science related activities or through a relationship with a health care professional. Successful candidates also had well-articulated connections to the ethos of health care which were expressed in specific stories from their work in clinical environments or personal experiences. Future candidates for CLS training might be more successful in the admissions process if they focus on obtaining direct experience in health care environments and clearly articulate how those experiences inspired them to work hard to obtain additional skills to contribute to care for patients. 


\section{ACKNOWLEDGMENTS}

In no particular order, I would like to thank the many people who have assisted me in completing this dissertation. I am grateful to Michael Bowling for agreeing to allow this project to move forward and Sharlene Washington for creating redacted copies of CLS applications for my review and for organizing the data so that it could be sent for statistical analysis. Felix Mbuga and Hung Tong under the supervision of Dr. Andrea Gottlieb pulled together the regression analysis and programmed the statistical analysis. I appreciate their patience with my questions and multitudinous spreadsheets. Five graduates of the program agreed to be interviewed and provided me with a deeper understanding of the admissions process. Having heard your stories in detail, I have even more respect for your professionalism, dedication, and commitment to our profession.

Thank you for sharing your time and your journey with me.

To my committee chair, Dr. Grinell Smith, thank you for being a good translator as I engaged in a new way of thinking about data. You were fantastically patient with my questions. You have taught me to appreciate the exceptions and the outliers and what they have to teach. I appreciate also the guidance and support from my committee members, Dr. Collette Rabin, who encouraged me to consider a qualitative approach, and Dr. Suzanne Campbell, who helped right size the project and lent a keen eye for detail to the final manuscript.

I appreciate my classmates in Cohort 5, especially Anne, Gerald, Richard, and Rafa. I hope we can continue to support each other and have more adventures together in the 
years to come. I also appreciate the efforts of Dr. Arnold Danzig and Dr. Bradley Porfilio in organizing the program for all of us and providing us with support.

I want to extend thanks to my immediate and extended family. To my husband, Sam, thank you for all the extras you picked up to give me the time and space I needed to get this work done, your unwavering confidence in my ability to finish, and your encouragement throughout the process. To my children, Sara and Norman, all that I do, I do for you. Thank you for your patience with my absences and the extra work that took me away from our family. My mother (a pathologist) introduced me to laboratory medicine and my father (an engineer) taught me to understand and love machines. My career has combined the best of what you taught me about the importance of helping others and the fascinating way machines can be used to learn more about the invisible mysteries that exist within and around us. Thank you for the inspiration. My three sisters, Ruth, Grace, and Clare all provided emotional support along with my friends, especially Lucia, Jay, Mi, Anna, Jovia, Cindy, and Rachel. If you're going to finish a dissertation in a pandemic, these folks will back your play.

Finally, to the thousands of laboratory professionals who have been instrumental in fighting the pandemic, thank you. When nature served us a nightmare, you stepped up, held the line, and worked harder than ever to make sure patients received the best care possible. You are heroes. Inspired by your efforts, I hope to use this research to help more people join us in this important and life-saving work. 


\section{TABLE OF CONTENTS}

List of Tables.........................................................

List of Figures...................................................... xi

List of Abbreviations................................................ xii

Chapter One: Introduction and Statement of the Problem........................ 1

The Unresolved Issue in Education........................................ 1

Prevalence and Impact of Unemployment Among American Youth......... 1

Academic Advising for Workforce Entry............................... 2

Entry into Allied Health Careers......................................... 3

Clinical Laboratory Careers - Pathways to Licensure..................... 3

California Requirements for Training................................. 4

Applicant Preparation - Academic and Work Experiences................. 5

Statement of the Problem................................................... 6

Significance of the Problem................................................... 8

Research Questions.................................................. 9

Initial Definitions.................................................... 10

Site Selection and Sample................................................ 11

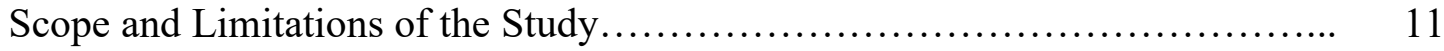

Scope.................................................................. 11

Limitations.................................................... 12

Assumptions, Background, and Role of the Researcher in the Study........... 13

Assumptions.................................................... 13

Background and Role of the Researcher............................. 13

Chapter Two: Literature Review......................................... 16

Social Cognitive Career Theory........................................ 17

Student Interest in Allied Health Professions................................ 19

Defining Allied Health Professions................................... 20

Developing an Interest in Allied Health Professions: Helpful Factors and

Barriers......................................................... 21

Allied Health Admissions Practices....................................... 23

Pre-admission GPA as a Predictor of In-Program Academic Performance.... 23

Pre-admission GPA, in Program GPA, as a Predictor of Certification Exam

Performance..................................................... 24

Standardized Tests in Admissions as Predictors of Program Performance... 26

Evaluation of Non-academic Skills.................................... 27

Gaps: Outcomes Tracked and Reported but Admissions Information is Not...... 28

Chapter Three: Research Design and Methodology......................... 30 
Purpose Statement..................................................... $\quad 30$

Research Questions................................................... 30

Research Design........................................................... 31

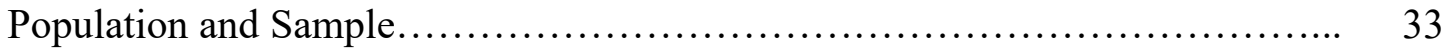

Selection Criteria for the Sample....................................... 34

Setting and Participant Selection....................................... 34

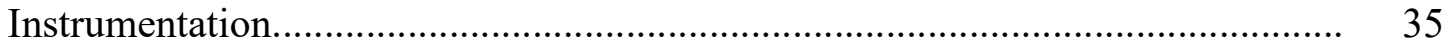

Data Collection Procedures............................................................................ 36

Organization of the Data Analysis..................................................................... 37

Quantitative Data Analysis................................................................................ 37

Statistical Analysis of the Sample Population.................................................. 38

Statistical Analysis for Research Question 1................................................ 38

Statistical Analysis for Research Question 2............................................... $\quad 39$

Statistical Analysis for Research Question 3 .............................................. 39

Qualitative Data Analysis................................................................................. $\quad 39$

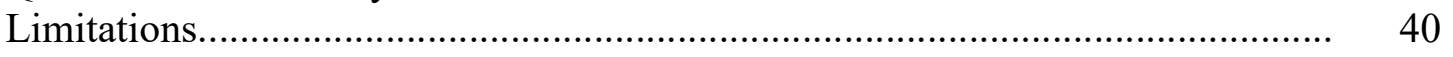

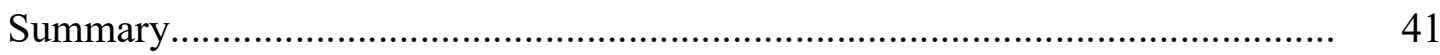

Chapter Four: Results.....................................................................................

Sample Profile....................................................................................... 43

Demographic Profile of the Sample..................................................................... 44

Age

Gender...................................................................................... 45

Race / Ethnicity............................................................................... 46

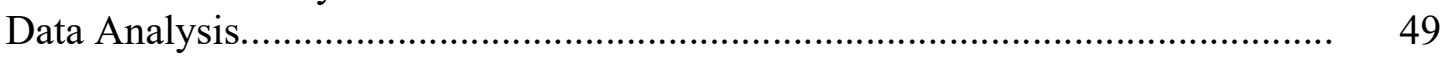

Findings and Discussion of Research Questions................................................. 49

Research Question 1........................................................................ 49

Research Question 2 ......................................................................... 50

Research Question 3 ...................................................................... 5

Research Question 4 .............................................................................. 51

Personal Interests and Background Inspire Interest in Learning Experiences...... $\quad 52$

Origin Stories Contextualize the Development of Personal Interests.............. 52

Refining A General Interest in Science to an Interest in CLS through

Application of Theory ............................................................................. 53

Self-efficacy Expectations: Soft Skills and Technical Skills............................... 54

Soft Skills...................................................................................... 55

Improving Patient Care ......................................................................... 56

Laboratory Techniques............................................................................ 5 
Barriers to Educational Experiences and Actions Leading to a CLS Career......... 59

The Barrier of Personal Loss Leading to Academic Struggle............................ 59

Family Responsibilities as a Barrier.............................................................. $\quad 60$

Understanding and Navigating American Interview Conventions as a

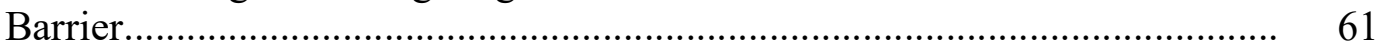

The Program Interview: Mutual Evaluation and Information Gathering............... 62

Showing the Education Coordinator You Fit................................................... 63

Making an Effort to Build Rapport with the Education Coordinator................ 63

Evaluation of the Clinical Site by the Candidate............................................. 64

Refining Their Approach and Learning from Others....................................... 66

Chapter Five: Key Findings, Conclusions, Discussion, and Recommendations for

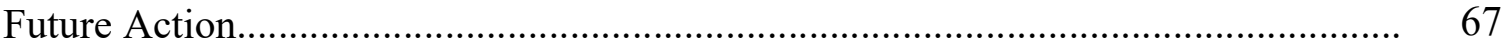

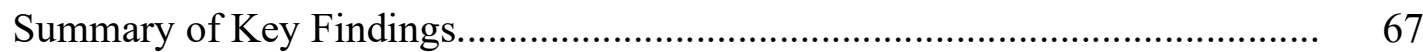

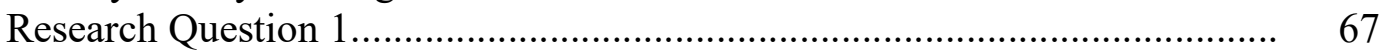

Research Question 2........................................................................... 68

Research Question 3 ....................................................................... 69

Research Question 4.......................................................................... $\quad 70$

Discussion and Conclusions............................................................................. 71

Choice Distal Contextual Affordances Described by Applicants................... $\quad 72$

Learning Experiences.............................................................................. $\quad 74$

Self-Efficacy and Outcome Expectations...................................................... 75

Goals and Actions................................................................................ 76

Barriers Modulating Goals and Actions........................................................ $\quad 76$

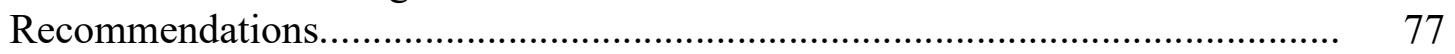

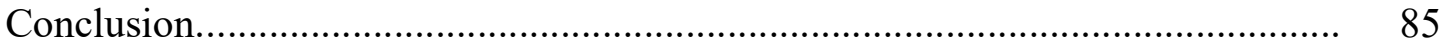

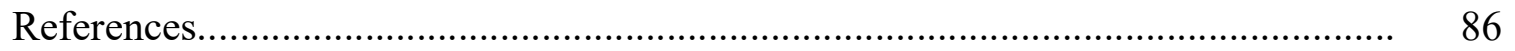

Appendix A: Interview Questions and Consent Form.............................................. 91

Appendix B: Details of the Statistical Analysis........................................................ 95 


\section{LIST OF TABLES}

Table 1. Summary of Data on Age Per Cycle and For All Applicants.......................................................................... 44

Table 2. Distribution of Gender Across Application Cycles, For All

Applicants .......................................................

Table 3. Distribution of Ethnicities in Individual Cycles and For All

Applicants.................................................

Table 4. Ethnic Distribution in Segments of the Laboratory Workforce..... 48

Table 5. Recommendations for Children 13 and Younger.................. 79

Table 6. Recommendations for High School Students.................... 80

Table 7. Recommendations for College Students.......................... 81

Table 8. Recommendations for Post-Baccalaureate Students............... 82 


\section{LIST OF FIGURES}

Figure 1. Social Cognitive Career Theory model............................................. 19

Figure 2. Distribution of genders in total applicant pool................................... 45

Figure 3. Distribution of ethnicities in total applicant pool................................. 46 


\section{LIST OF ABBREVIATIONS}

ACT - American College Testing AHPAT - Allied Health Professions Aptitude Test

ASCP - American Society for Clinical Pathology

CCR - California Code of Regulations

CLS - clinical laboratory science, or clinical laboratory scientist

GPA - grade point average

GRE - Graduate Record Examinations

LFS - Laboratory Field Services

MLS - medical laboratory scientist

NCLEX-RN - National Council Licensing Exam for Registered Nurses

SAT - Scholastic Assessment Test

SCCT - Social Cognitive Career Theory

SJSU - San José State University 


\section{Chapter One: Introduction and Statement of the Problem}

\section{The Unresolved Issue in Education}

Ideally, educational institutions help students identify interests, develop talents, and eventually pursue adult work, but in practice, many people face a rough transition from education to employment. Traditionally-aged college students (18-22 years old) face the challenge of answering the following two questions: "Who am I as an adult?" and "What do I want to do when I grow up?" Students expect their college degree will prepare them for work and increase their opportunity to pursue a career. The American College Freshman survey in 2015 reported that $85 \%$ of college freshmen rate as "very important" their college's ability to help them find a job, and 76\% rate as "very important" their ability to prepare for a specific career (Higher Education Research Institute, 2014). Just having a college degree makes it more likely that students will be able to take advantage of new jobs in a technology-driven economy (Fussell \& Furstenberg, 2005). Despite this potential for career preparation and discernment, many students leave college and become either unemployed or underemployed.

Prevalence and impact of unemployment among American youth. In October 2018 and 2017, unemployment in the United States was much higher among individuals in the 16-24-year-old range (8.3\%) than adults in the 45-54-year-old range $(2.7 \%)$ (United States Bureau of Labor Statistics, 2018). This discrepancy is problematic because youth experiencing job loss and unemployment early in their careers can experience greater levels of mental and physical health problems throughout their lives (Cassidy \& Wright, 2008; Hammarstrom \& Janlert, 2002; Lee et al., 2019). Cassidy and Wright 
(2008) assessed university enrolled students 6 months before and 9-12 months after graduation to determine their level of psychological distress and whether they engage in healthy behavior. Among the group that was employed in their desired job after graduation, the rates of psychological distress were significantly lower compared to those who were either unemployed or underemployed. Graduates employed in desired jobs also reported engaging in more health-promoting behaviors. The interests of academic institutions, students, and employers are all served best when graduates make a successful transition into the workforce. What remains an issue is how this can this be accomplished for all graduates.

Academic advising for workforce entry. One approach to academic advising is the Developmental Model (O'Banion, 2009). In this approach, many dimensions of a student's growth (e.g., life goals, vocational goals, program choice, course choice and registration) are addressed through an ongoing personal relationship between a student and a college counselor or faculty member. For instance, working directly with a trusted faculty mentor or academic counselor has been shown to help students navigate the academic institution and find experiences that help them transition successfully from school to work. Students with mentors tend to have better academic performance (Anderson \& Shore, 2008) and greater ease transitioning into the workforce, which increases the odds of full-time employment (McDonald, Erickson, Johnson, \& Elder, 2007). These findings suggest that illuminating pathways to work for both students and their advisors will amplify the effectiveness of these relationships. 
Entry into allied health careers. Sixty percent of health care providers

(approximately 5 million people) belong to one of the 80 occupations classified as allied health professions ("Allied Health Professions Overview," 2018). Students who are interested in pursuing a career in allied health face especially complex challenges. Most faculty advisors are not fully aware of the variety of health careers that are available or understand the varied requirements that must be met by Allied Health program applicants. Allied health training programs typically require applicants to have specific prerequisite coursework and work or volunteer experience in the field, which varies according to the field. Some of these requirements are stated explicitly as program prerequisites. Other requirements are unstated but usually known to those who are familiar with the field; codifying and publishing them will make them more available to advisors and students who are interested in exploring the diverse and complex paths that lead to these career options.

Clinical laboratory careers: Pathways to licensure. This dissertation study explores routes college students have followed to qualify for training as clinical laboratory scientists (CLSs). CLSs perform diagnostic tests to assist in the diagnosis and treatment of disease. California is one of 14 states that requires CLSs to be licensed and has more stringent requirements for training and licensure than any other state except New York. The requirements of state licensure define the minimum training and education an individual must have in order to do this work.

Clearly understanding the different pathways that can lead to admissions will be beneficial to those preparing to apply for training and should lower the cost in time and 
tuition spent qualifying for program entry. Acceptance into a clinical internship is the last critical step in qualifying for licensure and one of the most difficult barriers to overcome. For example, San José State University has one of the largest CLS Training Programs in California, accepting 30-50 students for training each year. Typically, approximately 200 individuals will apply for training each cycle, with an acceptance rate of $15-25 \%$.

California requirements for training. The California Business and Professions Code requires that training sites and trainees meet specific requirements. Training programs approved in California must comply with the California Code of Regulations (CCR) and are reviewed by Laboratory Field Services (LFS), a branch of the California Department of Public Health. California Code of Regulations allows for a number of different styles of program organization but the majority in California are $4+1$, that is, applicants have a bachelor's degree and qualify for a CLS training license before program entry. Degree and course requirements to qualify for a trainee license are explicitly stated in the CCR. While multiple pathways can lead to a trainee license, the most common is to finish a bachelor's degree and the equivalent of 16 semester units of chemistry, including general, organic, quantitative analysis, and biochemistry, 18 semester units of biology, including immunology, hematology, and medical microbiology, and 3 semester units of physics, including instruction in light and electricity. After obtaining a trainee license and a trainee position in an approved program, students must also complete clinical training for one year. Most training programs are a collaboration between an educational institution, which holds a national 
accreditation for the program, and multiple clinical sites that are individually approved by the state of California to provide hands-on training in laboratory methods.

Applicant preparation: Academic and work experiences. Most universities in the California State University system offer all of the courses that students need to qualify for training as a CLS; however, students often do not incorporate these classes into their plans before graduation and spend years after graduating with their bachelor's degrees taking classes to meet minimum academic requirements. This is costly in terms of time and additional tuition.

In addition to coursework and other academic qualifications, applicants must match to a clinical site which screens them for their academic qualifications, but the site will also evaluate a candidate's work experience and ability to articulate a personal commitment to the field during interviews. These interviews occur at the clinical site and the academic institution where the training program is housed. The decision to accept a student for training is a joint decision, with both the academic institution and the clinical site contributing in various ways. In the program I studied, clinical sites have right of refusal. Clinical sites only consider those students who qualify for an interview and can then indicate that they are only willing to take a subset of those students available to them. Applicants are matched based on their preference (if they prefer not to be placed at a site, they can refuse that site) and their rank compared to other students.

Beyond meeting the minimum requirements to qualify for training, applicants are not provided with information about what factors would help them to be more competitive in the application process. The academic institution has an interest in ensuring that accepted 
students have demonstrated their ability to manage the courses they will take as part of the program. The education coordinators from the clinical sites are laboratory managers, and it is reasonable to assume that they are looking for individuals that will fit with the team in the laboratory they lead or that they might prefer candidates with experience in a clinical setting. However, unlike other allied health professionals, factors that lead to success in admissions for CLS applicants have not been the subject of scholarly study. Further, qualities that are screened during the admissions process have not been mapped back to success in the program either in clinical performance or on the board exam taken after program completion. The opaque nature of this process makes it difficult for applicants or those advising them to know where to focus time and energy to optimize the chance of admission, and ultimately for program success.

\section{Statement of the Problem}

As admissions become more selective, the factors used to select students have the potential to become more extreme versions of existing minimum qualifications or begin to include requirements that are not explicitly part of the admissions process. This potentially creates a biased admissions process which is a problem of practice. Some applicants, by virtue of their socioeconomic status, life experience, or work history, have an advantage over other applicants because they have fulfilled unstated requirements for admission. Given the complexity of, and the lack of published studies on, the admissions process, it is difficult to expect students or their advisors to know exactly what factors to focus on in order to increase an individual student's chance of admission into these programs. 
In this dissertation, I identified and evaluated qualities which correlate to admission into the CLS Training Program at San José State University (SJSU) and map some of those qualities to program outcomes. Admission requires completion of prerequisite courses, submission of an application, and an interview. I also evaluated, via interviewing, what former program applicants thought were important characteristics for admission and how they prepared for the admissions process. I plan to evaluate if those characteristics align with characteristics that actually correlate to admissions and, through interviewing applicants who applied multiple times, describe how some applicants refine their approach in successive attempts at admission.

Successful candidates for CLS training possess a combination of qualities that include stated formal program requirements and unstated preferred skills that might not be obvious to someone who has not worked in the field. Most programs are coordinated through a university or a central hospital that affiliates with multiple clinical sites. Admissions decisions are made in collaboration between the institution that offers the training program and the clinical sites where the clinical training takes place. In the SJSU CLS training program, students are only admitted if a hospital agrees to accept them for training. The students are ranked based on their application (50\% weight), interview ( $40 \%$ weight), and an essay that is written at the time of interview (10\%). The educational institution that houses the program provides the application score, but representatives from clinical sites score the interviews and essays so that the final student score or rank is determined by both the clinical sites and their educational institution partner. Applicants rank the clinical affiliates of the program during the interview 
process. The applicant with the highest score is given first choice of affiliates. If the clinical site the applicant ranked highest is willing to accept that student, that training position is assigned and the next applicant's preferences are considered. This process is followed until all training sites have been assigned.

A training site coordinator's decision to offer placement takes into account academic performance, but it also depends on work experience, personality, and perceptions of "fit" with the current work culture. As such, even students who rank highly in academic domain may not get a placement if a clinical site coordinator determines that other factors do not align.

\section{Significance of the Problem}

This project sought to identify aspects of academic performance, work and life experience, and personal characteristics which successful applicants to the program possess to efficiently prepare, apply, and enter training. Many students who ultimately enter training to become a CLS have spent years between graduation and program entry working and have spent additional money taking classes they could have incorporated into their bachelor's degree to qualify for admissions. This project, by identifying factors that support admission to the program, should decrease the time and expense of preparing for this career by making success factors more explicit.

The stated formal program requirements for CLS training involve qualifying for the California CLS Trainee license by earning a bachelor's degree in the sciences and completing prescribed prerequisite courses in biology, chemistry, physics, and mathematics. The training program then allows students to earn a qualification for 
licensure by completing one year of study in a California approved program where at least $75 \%$ of the student's time is spent doing hands-on work in a licensed clinical laboratory.

Because training sites often hire their students after they qualify for licensure, there are unstated additional requirements that must also be met. Students must convince education coordinators at clinical sites that they will be a good match for the site and that they have the affective and psychomotor skills to do the job. Students often have to demonstrate some understanding of the "helping mission" of the hospital or laboratory where they train and articulate their alignment with that mission, and this can be difficult for students who have not worked in a clinical setting.

\section{Research Questions}

This dissertation study will identify aspects of academic performance, work and life experience, and personal characteristics that all successful applicants to CLS training programs share. This study will clarify for faculty and applicants those qualities that are most sought after and most worth cultivating or expressing as part of the application process. A full understanding of these qualities will allow future applicants to efficiently prepare themselves to apply and enter training. College faculty are expected to advise and guide students with a range of different career aspirations, but oftentimes faculty themselves have little or no experience in careers outside of academia.

In particular, this study will resolve the following research questions: 
1. What characteristics (age, gender, ethnicity, and academic performance) distinguish between applicants who are offered an interview to the program and those who are not?

2. What characteristics (age, gender, ethnicity, academic performance, and work experience) distinguish between applicants who are offered a placement after an interview and those who are not?

3. How do qualities selected for during the admissions process correlate to success on the American Society for Clinical Pathology (ASCP) certification exam required for CLS licensure?

4. What preparation did applicants make to qualify for admission?

\section{Initial Definitions}

American Society for Clinical Pathology: The agency which offers the Board of Certification exam for medical laboratory scientists (MLS) which is one of the exams accepted for CLS licensure in California.

California Business and Professions Code: The laws passed by the legislature which define various requirements for the licensure and approval of various professions and businesses in California.

California Code of Regulations: The rules which regulatory departments of the California State Government use to elaborate and enforce the requirements of the California Business and Professions Code.

Clinical Laboratory Scientist: An individual who performs waived, moderate, and high complexity testing for the purpose of diagnosing human disease. 
Hematology: The study of components of peripheral blood and bone marrow.

Immunology: The study of the immune system, its components and activities.

Medical Laboratory Technician: An individual who performs waived and moderately complex testing for the purposes of diagnosing human disease.

Medical Microbiology: The study of microorganisms which infect and cause disease in humans.

\section{Site Selection and Sample}

The participants in this study were all applicants to the CLS training program at San José State University (SJSU) for 2017-2018. SJSU is the site that I chose primarily because of the size of the program (it is the largest in California with more than 50 students trained each year), the diversity of clinical sites (urban and rural, northern and southern California, large and small hospitals), and my familiarity with the program.

\section{Scope and Limitations of the Study}

Scope. I examined paper applications from 2017-2018 admissions cycles. From the paper applications, I evaluated student GPAs in all college work, performance in prerequisite courses, the mode of delivery (online versus live, lab or lecture only, during undergraduate study or after), work experience, and basic demographic information such as gender, self-reported ethnicity, and age. For all students admitted to interview, I coded the self-reported work experience from student resumes. I also coded personal experiences which are described in the application essay for the program for six applicants in each application cycle. I chose three applications from those that were offered an internship and three from those that interviewed but were not offered a 
placement. I obtained the board exam performance information for accepted students and sought to identify any correlation between exam performance and factors selected for in the application process.

Through semi-structured interviews, I evaluated the steps five graduates of the program from these admissions cycles took to prepare for the interview for the program and other required aspects of program entry. I will select some applicants who were successful on their first attempt at admission to see what preparation they think was most helpful. I will also speak with individuals who applied multiple times to evaluate what their initial approach to this process was and how it changed over time.

Limitations. Admissions in Fall and Spring semesters are very different. While both cycles have typically had similar numbers of applicants, far more training positions are available in the Fall throughout California, and most students apply to multiple CLS training programs rather than just one. More applicants typically decline their offer of admission in the Fall, which increases the percent of applicants admitted in that cycle, and that may make it difficult to compare Fall and Spring admissions decision processes. I am including two Fall and two Spring cycles to make my understanding of the process more comprehensive. When analyzing the data, I assessed whether the admissions cycle that an applicant chose for their application correlates with the characteristics that applicants need to have in order to be successfully admitted. There was no statistically measurable effect.

Demographic data collected on the application forced individuals to make a binary choice for gender: male or female. There were a limited number of ethnic / racial 
categories to choose from and applicants that indicated multiple ethnicities had their data recorded as "no response."

\section{Assumptions, Background, and Role of the Researcher in the Study}

Assumptions. I assumed that applications revealed many of the characteristics that I hoped to evaluate in applicants, including work experience and personal characteristics. I also assumed that applicants are honestly reporting GPA, gender, age, and ethnicity on their application, as I am not attempting to determine that information from other sources. I am also assuming that applicants are accurately reporting their experiences in the application and that they did not bring any additional information to this process through the interviews on campus. It is possible that they might bring up additional personal or work experience in conversation with education coordinators or the program staff that would influence admissions in a way that I can't measure using these materials. However, my experience has been that applicants are generally honest, reveal a great deal through their application materials, and rarely bring in additional stories and experiences that are not listed in some way as part of the application.

Background and role of the researcher. I am a California licensed Clinical Laboratory Scientist and Nationally Certified Molecular Biologist Scientist and Medical Laboratory Scientist with the American Society for Clinical Pathology. I am also a former program director and instructor for the CLS students at SJSU. I teach courses in Hematology to undergraduates, many of whom are preparing for entry into CLS programs. I also teach molecular diagnostics courses for limited license students in the SJSU Clinical Genetic Molecular Biologist Scientist program. I work as an education 
coordinator at Kaiser Santa Clara Medical Center and accept students for clinical training as phlebotomists and Medical Laboratory Technicians from De Anza College and CLS students from SJSU. I have 19 years of experience evaluating candidates for clinical placement at various levels of practice in the laboratory and advising students and employees on climbing the career ladder.

As a manager in a clinical laboratory, I evaluate employees who work for me, and I have 11 years of experience watching individuals grow and develop their careers in the hospital setting. All of my students at Kaiser Santa Clara have successfully completed their training and passed their board exams on the first attempt. Several have moved up to greater levels of responsibility within the lab, as technical supervisors, shop stewards, and laboratory managers. In my role interviewing and evaluating applicants for the program, I have observed that students rarely go into their college career planning to work in the laboratory. It is something they may discover because of a relative or friend in the field or that they find after they graduate with a degree in science and are looking for a job. I hope to make it easier for people to find this profession earlier in their education so that they can more efficiently enter the profession.

This research also supports one of my personal goals in selecting candidates for training. I choose based on my understanding of how they will fit with the rest of the laboratory team, but also select for individuals who bring something that we lack or who have a strength that compliments an area where we are weak. I believe that a strong laboratory team has diverse members who bring many points of view to our decisionmaking processes and work collaboratively to provide our patients with the highest 
quality care. Ensuring that the admissions process is equitable helps me accomplish my goals. 


\section{Chapter 2: Literature Review}

This chapter provides a review of the literature pertinent to the following topics related to this project: (a) an introduction to social cognitive career theory as the theoretical framework supporting this research, (b) a description of student interest in allied health professions and barriers to entry, and (c) a review of allied health programs' admissions practices and the correlative and predictive value of criteria used in allied health admissions. These areas were selected to provide context for the questions considered in this research about the choices applicants make in preparing for careers in CLS. Most studies of allied health admissions are quantitative and focus on cognitive skills. There is limited research on the influence of non-cognitive factors on allied health program admissions, their ability to predict students' success in the program, or predict professional effectiveness. There is a gap in the literature describing those cognitive and non-cognitive skills in CLS admissions and their impact on equity during admissions.

The first section of this chapter reviews literature related to the social cognitive theory of career and academic interest, choice, and performance (Lent, Brown, \& Hackett, 1994). This theory fits the process of becoming an allied health professional in general, and CLS in particular, in that it treats the transition from school to work as a process including multiple steps: interest crystallization, career exploration, and cultivation of decision skills (Lent, Hackett, \& Brown, 1999). This is not a one-time event. Three key variables considered in social cognitive theory including self-efficacy, outcome expectations, and goals (Bandura, 1986) are examined further in the context of 
career exploration. This section includes a brief definition of each of these three ideas to inform the next section of the review.

The second section considers the process whereby students develop an interest in allied health professions. This research centered on studies of enrolled allied health students and specifically considered the positive influence of both social and circumstantial variables which might influence a student's choice of these professions. Researchers also describe barriers that students perceive when navigating the process of entering these professions.

The third section considers allied health program admissions practices and the correlative and predictive value of data collected during the admissions process with program performance and completion. Specifically, I review how academic performance, and performance on aptitude tests like the Allied Health Professions Aptitude Test (AHPAT) influence admissions. I then summarize findings from different allied health professions as to how these performance measures correlate to or predict program outcomes like program persistence, program academic performance, and performance on board exams.

\section{Social Cognitive Career Theory}

Social Cognitive Career Theory (SCCT), as proposed by Lent, Hackett, and Brown (1999), “focuses on several 'agentic' variables (self-efficacy, outcome expectations, goals) and on how they interact with other persons and environment variables (e.g., gender, race/ethnicity, social supports and barriers) in the context of people's career development (p. 297)." Self-efficacy refers to "people's judgements of their capabilities 
to organize and execute courses of action required to attain designated types of performances" (Bandura, 1986, p. 391) These traits are complex, and social cognitive theory assumes that competent performance at complex or challenging tasks requires skills and a strong sense of efficacy (Bandura, 1991). Outcome expectations involve imagining the consequences of performing particular behaviors. Bandura (1986) identified three classes of outcome expectations, including physical (e.g. monetary), social (e.g. approval), and self-evaluative (e.g. self-satisfaction) outcomes, that may impact career behavior. Finally, social cognitive theory presumes that goals play an important role in self-regulation of behavior. A goal may be defined as the determination to engage in a particular activity or to effect a particular future outcome (Bandura, 1986).

Lent, Brown, and Hackett (1994) state that "goals achieve their self-motivating quality by linking self-satisfaction to goal fulfillment (p. 85)." Lent, Brown, and Hackett (2000) describe distinct phases during which events potentially influence career choice. They describe career-relevant learning experiences as "choice distal contextual affordances." These feed into the development of expectations of self-efficacy and outcomes related to achieving a particular career. Closer to the school-to-work transition, the authors identify "choice proximal contextual affordances" like career network contacts and external barriers as moderating interests and choice of goals and actions that 
directly lead to entering a particular profession. Figure 1 is a diagram of the interplay between these elements.

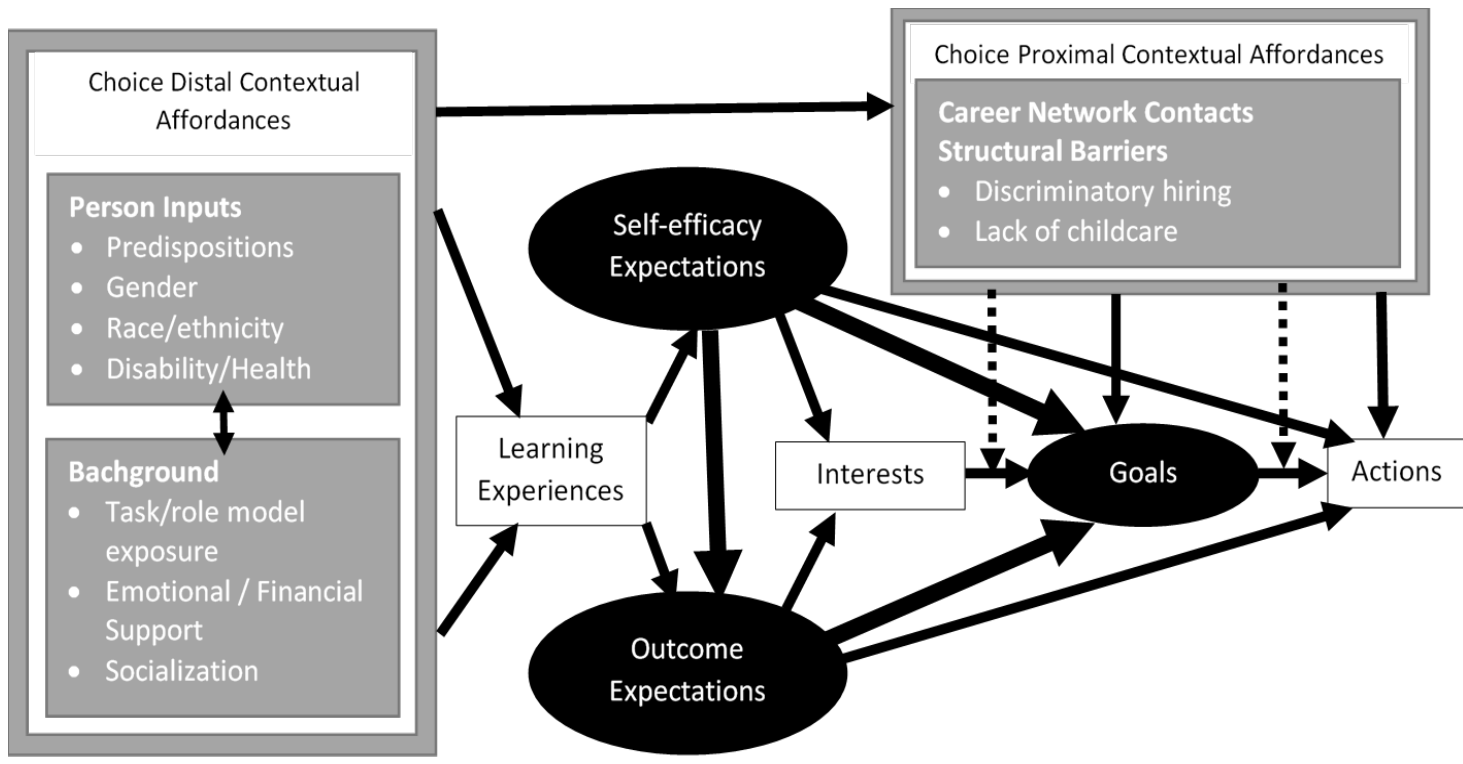

Figure 1. Social Cognitive Career Theory model. Adapted from "Toward a unifying social cognitive theory of career and academic interest, choice, and performance," by R. W. Lent, S. D. Brown, and G. Hackett, 1994, Journal of Vocational Behavior, $45(1)$, p. 88

\section{Student Interest in Allied Health Professions}

Lent, Hackett, and Brown (1994) identify the general qualities of self-efficacy, outcomes expectations and personal goals in driving the development of skills and abilities that lead to specific careers. How, then, do these play themselves out in specific careers? The following section first defines what the "allied health" professions are and then describe some of the choice distal and choice proximal factors which students report influence their choice of these careers. 
Defining allied health professions. CLS falls within the allied health professions, a diverse group of support professions in the health care industry. Allied health professions vary in their requirement for training and education, from on-the-job training up to doctoral education. The Associated School of Allied Health Professions defines these professionals as any individual in the health care field "that delivers services involving the identification, evaluation and prevention of diseases and disorders; dietary and nutrition services; and rehabilitation and health systems management" (Association of Schools Advancing Health Professions, 2020).

Many of the allied health professions have a mix of patient-facing activities and more technical activities that happen "behind the scenes." Phlebotomists, physical therapists, and occupational therapists are examples of practitioners whose activities center around interactions with the patient. Imaging technicians (e.g. radiology technicians, magnetic resonance imaging technicians, sonographers) and respiratory therapists are examples of occupations that require a mix of skills which include interacting with patients but also operating complex equipment. Pharmacists and CLSs are examples of individuals who work almost exclusively behind the scenes, with limited patient contact and highly technical training. Nursing is so broad a field that it exists across the spectrum described here, with some specialties requiring highly technical understanding (laser safety officers are typically nurses) and others almost exclusively focused on direct patient care (nurses working in hospitals, skilled nursing facilities, hospice, etc.). The professions which most closely resemble CLS in terms of their training requirements are those that require a bachelor's or graduate degree for entry level work - nursing, occupational therapy, 
pharmacy, physical therapy, and audiology. However, with the exception of pharmacy, all of those professionals spend more time with patients than CLSs would.

\section{Developing an interest in allied health professions: Helpful factors and barriers.}

Several factors are known to play a role in potential CLS students developing an interest in the field and beginning to see themselves as potential members of the profession. Interest can develop because of student interactions and exposure to individuals doing the work (Taylor, 1985). Taylor also observed that the transition to imagining oneself as a member of the profession is also enhanced by direct exposure to the job and observing the work and the rewards that come from doing the job. Baldwin and Agho (2003) noted that students developed interest in a profession by interacting with people they knew who worked in the field that they were studying or who worked in a related health care profession. Indeed, when allied health majors were asked what influenced them to choose that area for their focus in college, they cited social influences like high school and college faculty and counselors as the most influential (Barfield, Folio, Lam, \& Zhang, 2011).

Though students may develop an interest in allied health professions, there are a number of barriers they must overcome to gain admission to the training programs which allow them entry into the profession. Student ability to succeed in allied health programs is evaluated based on their academic skills as predicted by pre-program grade point average (GPA) and, in some cases, standardized exams. Student must evaluate how their own skills and abilities align with what is required for admission into training. When asked about their perception of barriers to entry into the field, one study found that 
students generally do not see insufficient academic preparation as a barrier to program entry (Barfield et al., 2011). However, the authors of the study did note that selfmanagement was an important predictor of student success in programs because of the potential conflicts between student commitments within school and their personal lives. Interestingly, students did not identify that as a barrier. These students were primarily entering allied health programs which admitted directly from high school or the junior year of college.

In a study focused on students in the speech and communications disorders professions, investigators did find that students with GPAs lower than a B + felt unsure about their ability to get into graduate training programs and more than half of the students were considering taking the Graduate Record Examinations (GRE) as second time because they felt their score was not sufficient to make them competitive applicants (Fuse, 2018). On average, student time spent studying each week and GPA fell as the number of hours students worked rose. More than $21 \%$ of students reported working more than 31 hours each week, most because they needed to support themselves financially and pay for school. While interest in the health professions may grow from exposure to those professionals and their work, students entering these programs do perceive barriers to entry and are sacrificing their educational achievement in order to work and live despite the realization that it may compromise their ability to get into the final stage of training they need to enter their profession of choice. 


\section{Allied Health Admissions Practices}

Despite the diversity of practice and differences in skills required for success in these professions, allied health admissions processes are remarkably similar in that they seek to evaluate student's academic skills, their personal qualities and experiences which help them practice successfully in their chosen role (Glazer \& Bankston, 2014; Goodyear \& Lampe, 2004; Kenny, 2010; Kudlas, 2006; Salvatori, 2001). Students' academic skills are typically evaluated using pre-enrollment GPA with some programs also evaluating science GPA as well. General academic ability is sometimes evaluated with a standardized exam though these vary depending on the discipline. Personal experiences can be evaluated through personal statements, interviews, and letters of reference.

Pre-admission GPA as a predictor of in-program academic performance. In one review, the author noted that "The evidence is overwhelmingly clear that pre-admission academic grades predict subsequent in-course academic performance in all professional disciplines” (Salvatori, 2011, p.161). In physical therapy programs (Payton, 1997), athletic training (Platt, Turocy, \& McGlumphy, 2001), and dental hygiene (Ward, Downey, Thompson, \& Collins, 2010), scholars note a link between pre-admission GPA and in-program GPA. Payton's (1997) conclusion is based on a meta-analysis of admissions practices in physical therapy programs over a 10 academic cycles from 19831994. Platt, Turocy and McGlumphy (2001) showed that high school GPA predicted performance in a college level athletic training program, but only predicted $14 \%$ of the variance in college GPA. Ward et al. (2010) showed that incoming GPA was a significant predictor of program completion and could somewhat predict student performance on 
their certifying exam but noted that college GPA at the end of the first year of study predicted better how students would perform on their exams. Kudlas (2006) found that pre-admission GPA in competitive radiology technician programs was one of only two variables that predicted retention in radiologic technician programs. In that study, inadequate academic performance accounted for nearly $40 \%$ of attrition. In another model developed that looked at physical therapy students, risk for academic probation was six times higher if student pre-admission GPA and GRE scores were not above a cutoff (3.5 GPA, verbal GRE $>410$, quantitative GRE $>570$ ) (Jewell \& Riddle, 2005). These findings were validated more recently in another study of students who took the physical therapy licensing exam after a revision in 2015 (Kume, Reddin, \& Horbacewicz, 2018) In aggregate, pre-program GPA predicts academic persistence and academic achievement within the program across a variety of professions.

\section{Pre-admission GPA, in-program GPA, as a predictor of certification exam}

performance. In addition to program completion, passing a certifying or licensing exam is often required before an allied health student can practice. How do pre-admission GPA map to success passing the certification exams for different professions? Multiple investigators have queried whether pre-admission GPA can be linked to licensing exam performance, with mixed results (Briscoe \& Anema, 1999; Carpio, O'Mara, \& Hezekiah, 1996; Kume et al., 2018; Salvatori, 2001; Yin \& Burger, 2003).

Briscoe and Anema (1999) found no correlation between improved exam performance and pre-enrollment GPA in students with GPA of 2.25-2.49 versus those with a GPA greater than 2.5 on the National Council Licensing Exam for Registered 
Nurses (NCLEX-RN). In-program performance (program GPA and number of inprogram courses with grade $<$ C) were better predictors. Similarly, Yin and Burger (2003) found that college GPA was a significant predictor of performance on the National Council Licensing Exam for Registered Nurses (NCLEX-RN), while other variables (high school GPA, ACT score, age, gender, and ethnicity) had no predictive quality. A study of Canadian nursing students found that their performance on high school chemistry and English courses was predictive of performance on the Canadian Nurses Association Testing Service Examination but performance in first year courses also correlated to good performance on the exam. The correlation between in-program performance for nursing students and exam performance was also observed by additional investigators (Kaddoura, Flint, Van Dyke, Yang, \& Chiang, 2017). Despite the mixed results from other investigators, Salvatori (2001) reported that a number of investigators had found a link between pre-program GPA and exam performance, though in some cases not a strong correlation.

Other allied health programs also found a mixed relationship between pre-admission GPA and exam performance. The pre-admission GPA of physical therapy graduates did not correlate to better exam performance on the National Physical Therapy Licensure Exam in a study of two programs in New York (Kume et al., 2018). A study of medical laboratory science students (MLS; another name for CLS used outside of California) in a program with junior year admission showed that college GPA and science GPA both correlated to successful performance passing the American Society for Clinical Pathology Board of Registry exam. Given the mixed nature of the results from multiple 
investigators, it is difficult to draw conclusions overall as to whether pre- admission GPA consistently predicts exam performance across all disciplines.

Standardized tests in admissions as predictors of program performance. The Scholastic Aptitude Test (SAT), American College Testing (ACT) test, the Allied Health Professions Aptitude Test (AHPAT), and Graduate Record Examinations (GRE) have all been used as factors in admission and used to evaluate whether or not student performance in the program or certification exams can be predicted (Goodyear \& Lampe, 2004; Harrelson, Gallaspy, Knight, \& Leaver-Dunn, 1997; Jewell \& Riddle, 2005; Kume et al., 2018; Platt et al., 2001; Salvatori, 2001).

Not all programs lend themselves to including these tests in the admissions process. At open enrollment colleges (most community colleges), often admissions are not competitive, and these tests are used retrospectively to evaluate if student performance or persistence could be predicted with an eye toward remediation or early intervention (Harrelson et al., 1997; Platt et al., 2001; Yin \& Burger, 2003). Programs that admit students after the completion of two or more years of college study are more likely to use the Allied Health Professions Aptitude Test for admissions but evaluate their students' performance compared to ACT or SAT scores retrospectively (Goodyear \& Lampe, 2004; Yin \& Burger, 2003). For graduate level programs (physical therapy, audiology), the GRE is used for admissions rather than the SAT or ACT (Jewell \& Riddle, 2005; Kume et al., 2018). For nurses, the predictive value of the ACT or SAT is not as great as that of the science GPA for college level prerequisite courses. 


\section{Evaluation of Non-academic Skills}

Because of the interactive, patient-facing nature of allied health work, a successful student has non-academic skills which influence their ability to succeed in training and as a clinician. As Platt et. al. (2001) observed:

Because of the great variance in their ability to predict professional outcomes, traditional selection criteria should not be the only factors used when considering students' applications. Other criteria, such as personal interviews, examination of student portfolios, student writing samples, and student motivation, should be considered. (p.143)

These aspects of the admissions process vary from program to program and are little studied compared to academic performance and test scores. One study of dental hygiene programs in the United States showed that the majority of programs did not evaluate a student based on community service work, previous experience in a dental hygiene office, perform pre-admissions interviews, or request personal statements or essays from applicants (Sanderson, 2014). Programs that did require those elements as part of the application process had higher rates of retention of students.

Gabard, Porzio, Oxford, and Braun (1997) evaluated the ability of interviews to predict student completion of a Masters of Physical Therapy program on a conventional schedule by surveying the directors of 46 physical therapy programs. They evaluated the cost, in terms of faculty time spent interviewing, and argued that because there was little difference in attrition between programs that interviewed and those that did not, it would be better to not interview. Academic qualities like GPA before entry and various subparts of the SAT or GRE have reliably predicted program performance in physical therapy students (Kume et al., 2018; Platt et al., 2001). 
Ten years later, Gabard (2007) wrote a commentary in which he argued for including a variety of non-cognitive qualities in the admissions process because of a growing recognition of two points: (a) Patients receiving care from providers of the same ethnicity or from providers that speak the same language have better health outcomes, and (b) the ethnic diversity in the existing health care workforce does not reflect the diversity found in the country as a whole. He suggested two courses of action which programs could follow to increase the diversity of experiences represented in a given pool of accepted students. For states where affirmative action was not allowed, he recommended developing holistic admissions methods that evaluate socioeconomic status, service goals, perseverance over obstacles, an essay on the potential issues encountered working with diverse populations or, where legal and appropriate, race and ethnicity. He also advocated for supporting each candidate with a thorough and holistic review. He argues against a hard cut-off score despite the fact that other investigators have shown that to be linked to persistence and adequate performance in the program because of the disproportionate burden this places on minority candidates who typically do not score as well as their white, non-Hispanic peers. Interviews and essays, viewed through the lens of inclusion and diversity, are a desirable element in the admissions process. A similar argument has been made by multiple investigators (Danek \& Borrayo, 2012; Glazer \& Bankston, 2014; Goode, Dunne, \& Bronheim, 2006; La Veist \& Pierre, 2014).

\section{Gaps: Outcomes Tracked and Reported but Admissions Information is Not}

The focus of scholarship in this area has been tracking student qualities assessed at the time of admissions against their performance (academic, clinical, or on certification 
exams) in the program. None of the investigators in these studies reported the average performance or exam scores of students who were not admitted to a program. It is possible, therefore, to correlate student performance to various qualities applicants possessed at the time of admission. However, it is not possible to know if the students who were not admitted had scores that were equivalent to those of students who got into the programs. This is significant because while it is good to know if an admitted student is likely to succeed, it is equally important to know if the admitted students are more likely to have attributes linked to success than those who are not admitted. Without the ability to distinguish between those who display the potential for success and those who do not, an admissions decision seems more like a lottery than a rational, selective system. It is also difficult to advise students preparing for program entry when it has not been established that the factors that correlate to persistence, academic achievement, and successful passage of the certification exam are actually different between those who were admitted and those who were not. This project sought to establish both the qualities that differentiate students who are admitted from those who are not and to correlate preadmission qualities to performance on the national board exams. 


\section{Chapter Three: Research Design and Methodology}

This chapter presents the methodology used to address the research questions of this study. The chapter includes the purpose, research questions, rationale for the research design, and research design. This description of this study also includes population and sample, instrumentation, data collection procedures and analysis, and limitations of the study.

\section{Purpose Statement}

This project sought to identify those characteristics students possess that correlate to admission clinical training for licensure as a clinical laboratory scientist (CLS) in California. To evaluate this, I used information collected as part of their applications to the program, including demographic data (age, gender, ethnicity), grade point average, and performance in prerequisite courses. The application also includes a resume and personal statement which I used to evaluate the applicants' work and personal experiences. In addition, I sought to clarify if performance in required prerequisite courses correlated to a score in subject specific sections of the certifying examination from the American Society for Clinical Pathology (ASCP). Finally, I describe how individual students prepared for their interviews and the application process to better

understand how their experience fits the Social Cognitive Career Theory (SCCT) model.

\section{Research Questions}

For this study, I investigated the following: 
1. What characteristics (age, gender, ethnicity, and academic performance) distinguish between applicants who are offered an interview to the program and those who are not?

2. What characteristics (age, gender, ethnicity, academic performance, and work experience) distinguish between applicants who are offered a placement after an interview and those who are not?

3. How do qualities selected for during the admissions process correlate to success on the ASCP certification exam required for CLS licensure?

4. What preparation did applicants make to qualify for admission?

\section{Research Design}

This study is a correlational, descriptive study performed with mixed methods. Creswell (2005) states that correlational research is used when researchers "seek to relate two or more variables to see if they influence each other" (p. 325). Tracking the demographic and academic performance data for applicants and using statistical analysis to correlate those with board exam performance all meet this standard. Omair (2005) notes that a descriptive study attempts "to generalize the findings from a representative sample to a larger target population" (p. 153). This project qualifies as descriptive in that I observed and reported on the investments applicants made in their human capital, their use of social capital, and their display of cultural alignment with the values of allied health professionals. A summary of these observations will be made available to students and their advisors to help them make strategic choices in their preparation for this process, a generalization of the research. 
A mixed methods approach is appropriate for this project because neither quantitative nor qualitative methods alone could sufficiently address the research questions, an approach supported by other researchers (Ivankova, Creswell, \& Stick, 2006). Quantitative methods are an appropriate way to evaluate if the demographic characteristics of the total applicant pool (age, gender, ethnicity) and academic performance (GPA and grades in specific courses) differ from the group admitted to interview, and the group accepted for training. For allied health admissions processes, investigators have used these methods to correlate admissions criteria with in-program performance (Jewell \& Riddle, 2005; Platt et al., 2001; Salvatori, 2001; Sanderson, 2014) and board exam performance (Kume et al., 2018; Wolkowitz \& Kelley, 2010; Yin \& Burger, 2003). Several authors have also used these methods to study whether CLS student pre-admission GPA (Solberg, 2015) or pre-admissions exams like the Allied Health Professionals Aptitude Test (Goodyear \& Lampe, 2004) predict performance on the ASCP Board Exam.

Qualitative methods were used in an explanatory fashion to help understand aspects of applicant preparation that could not be captured quantitatively as described by other researchers (Creswell, 2005, p. 515). In remarking on the limitations of one quantitative study of admissions characteristics of six different allied health students, Platt (2001) observed that academic performance measures like GPA could predict program success but accounted for only $14 \%$ of the variance in program performance. Salvatori (2001) suggested "other, perhaps non-cognitive variables such as work experience, interpersonal skills, motivation, maturity, empathy and ethical integrity are contributing to both 
academic and clinical performance outcomes" (p.170). Because of the variety of documents included in the application, it is possible to evaluate both the cognitive and non-cognitive skills alluded to by these investigators and create a nuanced picture of the successful applicant.

Semi-structured interviews with select program graduates allowed further refinement of my understanding of the successful applicant's personal investments in this process. I used a grounded theory approach to correlate efforts made by individual successful applicants with general observations about the qualities shared by all successful applicants. This allowed me to develop a "theory" of the actions a successful applicant must engage in to navigate the admissions process. Grounded theory, using the methods of Corbin and Strauss (2014) allows the investigator to develop a theory that explains a process. These interviews, along with data collected from the applications provided a multidimensional perspective of applicants and their preparation process. I then showed how their process fit with the activities predicted and described by the SCCT model.

\section{Population and Sample}

Analysis in phase one of the study considered differences between three groups in the 2017 and 2018 application cycles for the CLS program at San Jose State University: applicants who are not admitted to interview, applicants admitted to interview but not admitted for training, and applicants admitted for training. Self-reported demographic information and academic performance metrics for the participants was collected. In 
phase two of the study, I interviewed five program graduates about their experiences applying to the program.

\section{Selection Criteria for the Sample}

Setting and participant selection. The sampling method used was a mix of purposeful and convenience sampling. Application review was purposeful sampling. The applications for the SJSU CLS program from the 2017 and 2018 admissions cycles were chosen for study because successful applicants completed program requirements and took the ASCP certification exam for generalist Medical Laboratory Scientists by the time the research began. For phase two of the project, I used convenience sampling to select graduates of the program from the 2017 and 2018 application cycles for semi-structured interviews. This sampling method was chosen because I am limited to volunteers "willing and available to be studied" (Creswell, 2005, p.149). Their experiences were aligned with quantitative and qualitative data from the applications. Those who volunteered to be interviewed were from different clinical sites and application cycles. In phase one, I excluded incomplete applications from analysis. If applicants had attempted admission multiple times, I included all attempts in the analysis. If applicants were accepted for clinical training but decline the offer of admission, I included their data in the data analysis for RQ1 and RQ2 but was not be able to include them in the correlation of preadmission qualities to ASCP exam performance. In phase two, I excluded any graduate of the program with whom I have a supervisory relationship from the request for participation. 


\section{Instrumentation}

Phase one of this research did not use an instrument. In phase two, I used a validated survey of self-rated interview effectiveness as a starting point for more open-ended questions in my semi-structured interviews. This interview approach is consistent with Creswell (2005, p. 217) who observed this approach would "permit you to explore reasons for responses to the close ended questions." It also allows for elaboration of individual graduates' experiences so that "participants can best voice their experiences unconstrained by any perspectives of the research or past research findings" (Creswell, 2005, p. 214).

The survey I used, developed by Higgins and Judge (2004), was validated in the context of a study of the actions an interviewee can take to increase their chances of being offered a job. The interview process for the CLS program resembles job interviews in the sense that the interviewers are lab managers choosing students they believe will make good future employees. This provided a good jumping off point of validated positive behaviors that I explored more through open-ended questions. See Appendix A for a list of the questions on the survey. The survey asks the participant to rate how they engaged in different activities at the time of the interview to influence the recruiter's positive perception of their candidacy for a job. In their study, Higgins and Judge (2004) validated that candidates who reported engaging in "ingratiating" or influencing activities were more successful in getting a job.

The interviews with graduates explored several dimensions of preparation with multiple questions: showing interest in the organization, aligning with the interviewer, 
and maintaining a positive demeanor during the interview. In the original study, candidates showed interest in the organization either by complimenting the organization or by expressing enthusiasm or "goodness of fit" with the organization. There are also several questions which ask about the interest the candidate took in the interviewer and how they showed alignment with the interviewer's specific interests. Finally, there are questions about non-verbal behaviors, smiling and eye-contact. Each of these was a starting point for exploration of the applicant's approach to research about the organization, their willingness or ability to connect with the interviewer, and their own perception of their affect during the interview. At the conclusion of the interview, I asked about basic demographic information for that candidate to help align the findings from the interviews with the quantitative data from the applications.

\section{Data Collection Procedures}

This section describes data collection procedures. Guided by accepted ethical, valid, and succinct methods (Creswell, 2005; Creswell \& Poth, 2018; Ivankova et al., 2006), in phase one of the study, CLS program staff redacted applications for the 2017 and 2018 admissions cycles, removing all identifying information, transcripts, and letters of recommendation. They were made available to the researcher with coded identification linked to ASCP exam results. In phase two, a request for participation was sent to all graduates from the 2017 and 2018 cycles. Five individuals volunteered to participate in this research. Those that consented to be interviewed participated through Zoom using the survey developed by Higgins and Judge (2004) as a structured guide. Interviews were 
recorded on a password protected device and sent to Rev.com for transcription.

Participants were referred to using a pseudonym to protect their anonymity.

\section{Organization of the Data Analysis}

Data for both the quantitative and qualitative data was organized and aligned with the research questions. The data analysis included comparison of demographic characteristics of each group of interest and an evaluation of the data for shifts in demographics between the three groups of interest. It also included calculation of the predictive power of academic performance measures (grade point average and grades in individual undergraduate courses) on whether students pass the ASCP certification exam. This was compared to the findings in the literature regarding CLS students from other programs (Goodyear \& Lampe, 2004; Solberg, 2015).

\section{Quantitative Data Analysis}

I used Microsoft Excel to develop descriptive, inferential, and comparative statistics for each of the demographic qualities, academic performance collected from the applications of all individuals in the pool. I also evaluated if grades in prerequisite courses predict performance on the certifying board exam.

All complete applications were evaluated for self-reported demographic information (age, gender, ethnicity). In this phase of the research, I calculated demographic statistics for the application pool as a whole and then compare the characteristics of subgroups of those applicants that are offered interviews and those that are not. Microsoft Excel was be used for calculation of descriptive statistics (mean and standard deviation). Applicants were subset by the cycles they applied, and a logistic regression was fitted using R. 
The details of the statistical analysis and results from that analysis can be found in Appendix B.

Statistical analysis of the sample population. Descriptive statistics were generated for the total applicant pool, and for the subsets of those offered interviews and those who are not. Mean and standard deviation were reported for student's age for each group. Gender was reported as a forced binary as part of the application, male or female. This was due to the structure of the application questionnaire and not the choice of the researcher. The total number and percent of each gender was reported for each group. Applicants were encouraged to choose one ethnicity on a list which included the categories Black - Non-Hispanic, Asian / Pacific Islander, White - Non-Hispanic, Hispanic, and American Indian/Alaskan Native. I calculated the number of individuals of each ethnicity and the percentage of their representation in each group. Applicants have the option to skip all or part of the demographic section. Some applicants chose to report none or only part of the requested information. I reported on all the information included. I did not exclude applications with partial demographic data.

Statistical analysis for Research Question 1. Applicants were subset by the cycles they applied, and a logistic regression was fitted. Four separate logistic regression models were created to evaluate which (if any) of the characteristics studied influenced if an applicant was offered an interview. The response variable was interview, and the predictors (independent variables) were GPA, degree, age, gender, and ethnicity. For missing ages and GPA, mean imputation was used for each cycle. 
Statistical analysis for Research Question 2. To answer this question, similarly to the "interview" models, applicants were subset by the cycles they applied, and a logistic regression was fitted. This gave four logistic regression models, one for each of the four cycles, which sought to determine if age, gender, ethnicity, GPA, and work experience influenced whether a student achieved a placement in the program. The response variable was placement, and the predictors (independent variables) were GPA and all the ten work experience variables (hospital lab, medical experience, clinical lab experience, biotech lab experience, research, volunteer work, customer service, teaching, and military experience).

Statistical analysis for Research Question 3. I converted letter grades to their numerical equivalent in grade points $(\mathrm{A}=4, \mathrm{~A}-=3.7$ etc. $)$. Multiple linear regression models were fit for each of the three individual subjects microbiology, hematology, and immunology using the CLS exam individual subject score as the response variable. The incoming grade in the subject and the application cycle (Spring 2017, Fall 2017, Spring 2018 and Fall 2018) were used as the two predictor variables.

\section{Qualitative Data Analysis}

Qualitative data was collected from the applications and from interviews with program graduates to explore further their experiences preparing for and navigating the CLS application process. In phase one of the project, data about work, volunteer, and personal experience was collected from the resume and a personal statement included with the application. In phase two of this project, I interviewed some of the graduates from the CLS program to learn more about how they prepared for the interview. In both 
phases of this project, I used Grounded Theory (Corbin \& Strauss, 2014) to discover those factors and actions common to successful and unsuccessful applicants to the CLS program. Grounded Theory allows the combination of qualitative and quantitative data to describe processes of interest (Chun Tie, Birks, \& Francis, 2019). Using the systemic and analytical coding methods of Corbin and Strauss (Creswell \& Poth, 2018, p. 85), "the investigator seeks to systematically develop a theory that explains process, action, or interaction on a topic."

Following Merriam's (1998) description of the grounded theory approach, I crosschecked my initial interpretations within one data set (interviews of programs graduates) against other observations made within and across data sets (e.g. essays and resumes from applications). I then developed relevant categories using the method of constant comparison (Merriam, 1998).

\section{Limitations}

In phase one, the data collected from the applications was self-reported data. I did not have transcripts or other documents to validate GPA or grade information provided to me. A review of the literature does not speak to the reliability of self-reported GPA and course grade on applications. However, past review of applications in previous application cycles I conducted prior to the beginning of this project suggests to me that the vast majority of the time, applicants faithfully report their grade and GPA information on the application. Some of the demographic data was missing as some applicants decline to provide that information as part of their application. As expected, this was a small percentage of the overall population in the study. 
In phase two, the limited number of interviewees constrained the breadth of experiences described. This limited my ability to evaluate the preparation made by applicants who placed in different locations throughout California. It also limited my ability to tell the story of applicants with different life experiences - single parents, those with different types of previous careers, recent college graduates, etc..

This project considered only four admissions cycles at one school. While I believe that these results are generalizable for all programs, their utility outside of California is moderated by the configuration of the program at SJSU (post-baccalaureate clinical year only rather than a full bachelor's degree or master's degree). Education coordinators heavily influence the selection of students in the SJSU. They might select students based on different qualities than those considered in a more traditional university based admissions process.

\section{Summary}

These data collection methods speak to each element of the theoretical underpinning this work. The SCCT proposes that the interaction between self-efficacy, outcome expectations, and goals leads to specific actions which allow individuals to work toward a career goal. Contextual affordances which are acquired distal to the formation of career goals such as personal characteristics (gender, race/ethnicity, age) and background contribute to the learning experiences people have as they develop their sense of selfefficacy and their expectation of outcomes from their efforts. These were tracked for all applicants to the CLS program to determine if they correlate to success in navigating various parts of the CLS application process. There are also contextual influences 
applicants experience proximal to their entry into their chosen career which include access to career networks and access to various types of support. Students with more connection to health professions through their families and friends may have social networks that make it easier to obtain experiences and jobs which prepare them for these professions and family or other supporters willing to provide monetary and emotional support while they prepare for training. This study explored how applicants signal their alignment with the mission of health care and their understanding of the field through their essays, resume, and in their preparation for the interview. It is anticipated that clarifying which characteristics were helpful in program admission will allow individual students and their advisors to evaluate their preparation and to target activities and experiences to align better with past successful applicants to these kinds of programs.

This research validated the fairness of the selection process for applicants, determining if the admissions process itself is a structural barrier for certain groups who wish to enter this profession based on personal characteristics unrelated to their ability to succeed as laboratory scientists (age, gender, ethnicity). 


\section{Chapter Four: Results}

This study sought to determine which characteristics contribute to successful navigation through the CLS admissions process. Specifically, I sought to determine:

1. What characteristics (age, gender, ethnicity, and academic performance) distinguish between applicants who are offered an interview to the program and those who are not?

2. What characteristics (age, gender, ethnicity, academic performance, and work experience) distinguish between applicants who are offered a placement after an interview and those who are not?

3. How do qualities selected for during the admissions process correlate to success on the ASCP certification exam required for CLS licensure?

4. What preparation did applicants make to qualify for admission?

Quantitative and qualitative data was collected from applications, essays, and via interviews with graduated students to further elaborate the experiences of individuals navigating this process as detailed in the next section.

\section{Sample Profile}

Quantitative data was collected from all complete applications submitted in the 2017 and 2018 admissions cycles $(n=485)$. Applications that were missing transcripts, letters, or essays were considered "incomplete" and excluded from the study. Of those, 24 applications with essays were chosen for further examination and coding for qualitative data. I selected six applications from each admission cycle, three from candidates admitted for internship and three from candidates who were interviewed but not admitted. 
I also interviewed five graduates of the program about their experience preparing for their application and interview. Essays from applicants not admitted to interview were not available for evaluation. To recruit candidates for interview, I sent out an e-mail requesting participation from all graduates from the 2017 and 2018 admissions cycles. I interviewed everyone who responded to the request for participation in the research. Interviews lasted for approximately 25 minutes and were conducted online via Zoom. Each interview was recorded and transcribed verbatim.

\section{Demographic Profile of the Sample}

Age. Reporting of age, gender, and ethnicity was voluntary. About $20 \%$ of all applicants did not report age. This was consistent for all application cycles. The average age at time of application was 29 with a standard deviation of 5.88. Applicants in the Spring 2017 cycle were slightly older on average (30.32 years old) but the average age of applicants in other groups was within half a year of 29. See Table 1 for details.

Table 1

Summary of Data on Age Per Cycle and For All Applicants

\begin{tabular}{lccccc}
\hline & Average & $\begin{array}{c}\text { Standard } \\
\text { Deviation }\end{array}$ & $\begin{array}{c}\text { No } \\
\text { Answer }\end{array}$ & N & $\begin{array}{c}\text { All } \\
\text { Applicants }\end{array}$ \\
\hline Spring 2017 & 30.32 & 6.20 & 27 & 90 & 117 \\
Fall 2017 & 28.54 & 5.35 & 28 & 107 & 135 \\
Spring 2018 & 28.97 & 6.25 & 25 & 83 & 108 \\
Fall 2018 & 28.49 & 5.71 & 24 & 101 & 125 \\
All Applicants & 29.04 & 5.88 & 104 & 381 & 485 \\
\hline
\end{tabular}


Gender. Gender was queried as part of the application as a binary choice of male and female. Overall, the applicant pool predominantly identified as female (52\%) with $32 \%$ of applicants reporting that they were male. Sixteen percent of applicants chose not to answer the question. See Figure 2 for a representation of the distribution of these results for the total applicant pool. The distribution of answers to this question was consistent across the four cycles. Table 2 contains detailed information on distribution of genders.

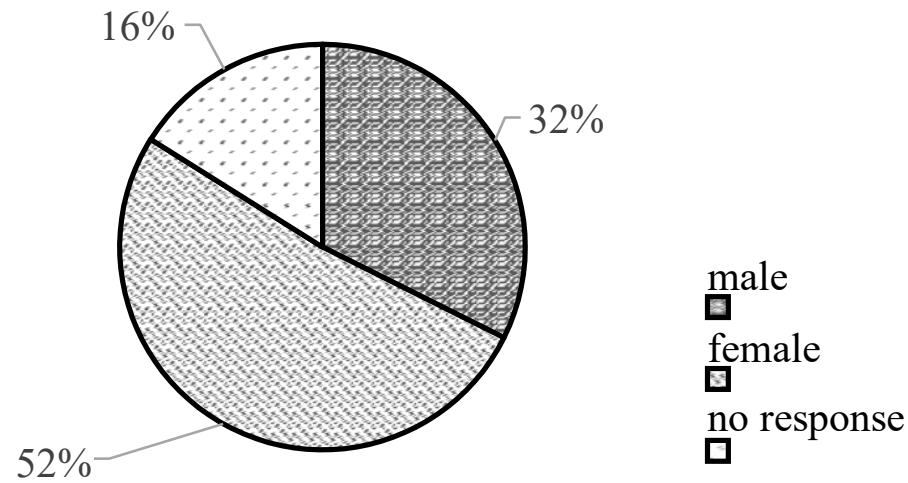

Figure 2. Distribution of genders in total applicant pool.

Table 2

Distribution of Gender Across Application Cycles, For All Applicants

\begin{tabular}{lcccc}
\hline & Male & Female & No Response & $\mathrm{N}$ \\
\hline Spring 2017 & $32 \%$ & $54 \%$ & $14 \%$ & 117 \\
Fall 2017 & $30 \%$ & $56 \%$ & $14 \%$ & 135 \\
Spring 2018 & $32 \%$ & $46 \%$ & $21 \%$ & 108 \\
Fall 2018 & $34 \%$ & $50 \%$ & $16 \%$ & 125 \\
All Applicants & $32 \%$ & $52 \%$ & $16 \%$ & 485 \\
\hline
\end{tabular}


According to the 2019 ASCP Survey of Medical Laboratories, the distribution of genders within the medical laboratory scientist (MLS) profession is $80.9 \%$ female and $19.1 \%$ male (this survey also forces a binary choice of gender). Men are more represented within SJSU applicant pool compared to the national labor pool for MLS.

Race / Ethnicity. As part of the application, candidates were given the following choices to self-identify race/ethnicity: Asian, Black, Hispanic, Native American / Alaskan Native, White. They were asked to pick one category. If more than one was marked, they were included in the "no response" group. For all applicants in all cycles, no ethnic group was in the majority. Asians were most represented (47\%) followed by White (22\%), Hispanic (10\%), and Native American (1\%). Seventeen percent of applicants chose not to answer this question or marked multiple answers. See Figure 3 for a summary of the distribution of ethnicities for all applicants.

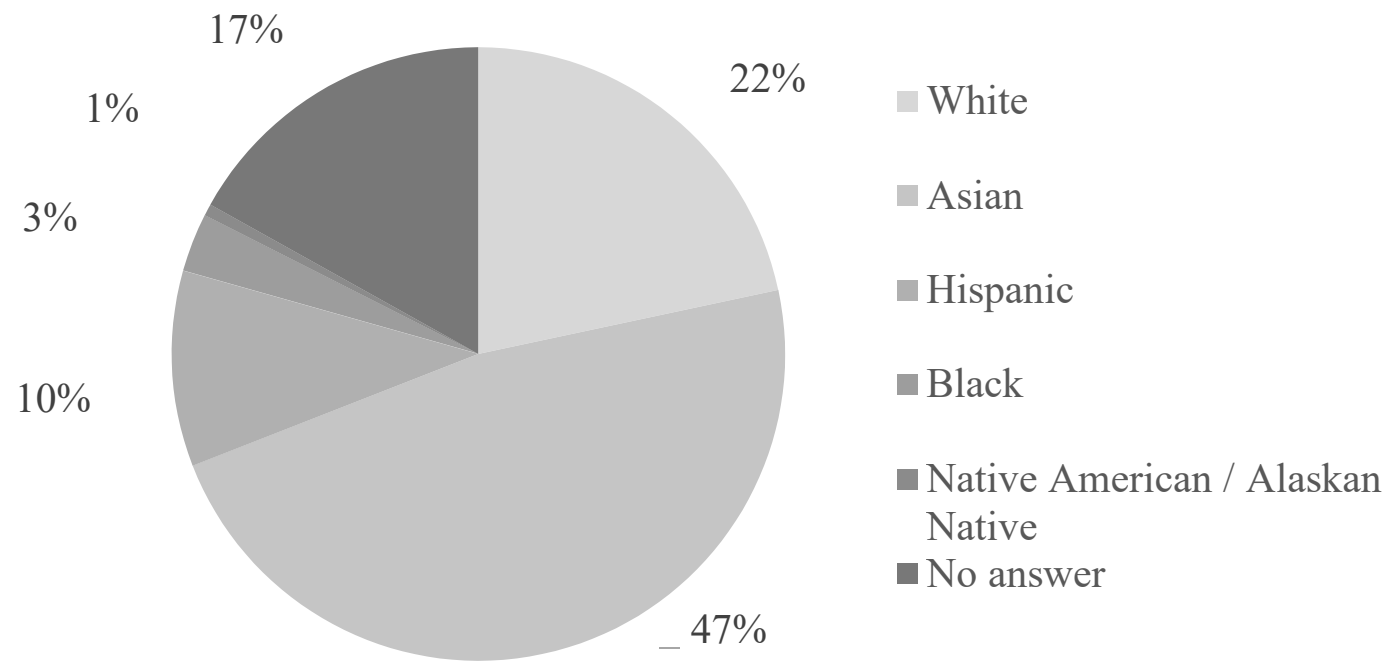

Figure 3. Distribution of ethnicities in total applicant pool. 
Distribution of ethnicities in each individual cycle showed little variation compared to the distribution in all applicants studied. See Table 3 for details of ethnic distribution.

Table 3

Distribution of Ethnicities in Individual Cycles and For All Applicants

\begin{tabular}{|c|c|c|c|c|c|c|c|}
\hline & White & Asian & Hispanic & Black & $\begin{array}{c}\text { Native } \\
\text { American } \\
\text { / Alaskan } \\
\text { Native }\end{array}$ & $\begin{array}{c}\text { No } \\
\text { answer }\end{array}$ & $\mathrm{N}$ \\
\hline Spring 2017 & $25 \%$ & $50 \%$ & $4 \%$ & $3 \%$ & $0 \%$ & $18 \%$ & 117 \\
\hline Fall 2017 & $24 \%$ & $45 \%$ & $11 \%$ & $4 \%$ & $0 \%$ & $15 \%$ & 135 \\
\hline Spring 2018 & $17 \%$ & $44 \%$ & $15 \%$ & $3 \%$ & $2 \%$ & $20 \%$ & 108 \\
\hline Fall 2018 & $20 \%$ & $51 \%$ & $11 \%$ & $2 \%$ & $1 \%$ & $15 \%$ & 125 \\
\hline $\begin{array}{l}\text { All } \\
\text { Applicants }\end{array}$ & $22 \%$ & $47 \%$ & $10 \%$ & $3 \%$ & $1 \%$ & $17 \%$ & 485 \\
\hline
\end{tabular}

I compared the distribution of ethnicities in the SJSU applicant pool to those reported for the medical laboratory workforce as a whole (as reported by Garcia, Kundu, and Fong, 2020) and to those reported by the United States Census Bureau (2019) for the 
general United States population and in the state of California. They differ substantially as shown in Table 4.

Table 4

Ethnic Distribution in Segments of the Laboratory Workforce

\begin{tabular}{|c|c|c|c|c|c|}
\hline & White & Asian & Hispanic & Black & $\begin{array}{c}\text { Native } \\
\text { American / } \\
\text { Alaskan } \\
\text { Native }\end{array}$ \\
\hline SJSU Applicants & $22 \%$ & $47 \%$ & $10 \%$ & $3 \%$ & $1 \%$ \\
\hline $\begin{array}{l}\text { State of California } \\
\text { General Population }\end{array}$ & $36.5 \%$ & $15.5 \%$ & $39.4 \%$ & $6.5 \%$ & $2.1 \%$ \\
\hline $\begin{array}{l}\text { ASCP } 2019 \text { Lab } \\
\text { Workforce }\end{array}$ & $74.5 \%$ & $8.17 \%$ & $6.13 \%$ & $7.56 \%$ & $1.1 \%$ \\
\hline $\begin{array}{l}\text { National Census } \\
\text { General Population }\end{array}$ & $60.1 \%$ & $5.9 \%$ & $18.5 \%$ & $13.4 \%$ & $1.5 \%$ \\
\hline
\end{tabular}

Nationally, the workforce is dominated by Whites with all other groups underrepresented compared to their representation in the general United States population. Comparing the distribution of ethnicities within the SJSU CLS program applicants to the distribution of ethnicities in the national laboratory workforce, general U.S. population, or state of California shows Asians are overrepresented in the program and all other groups are underrepresented, with one exception. Nationally, $6.13 \%$ of the laboratory workforce is Hispanic; ten percent of SJSU CLS applicants are Hispanic. This means that Hispanics are underrepresented in the SJSU applicant pool compared to the population in the state of California (39.4\% Hispanic) even though they are overrepresented compared to their proportion of the national laboratory workforce and the U.S. population. 
These percentages are aligned in the Table 4 but are not entirely comparable. The ASCP survey and the United States Census Bureau recognizes Native American and Native Alaskan as two separate groups. For the purposes of comparison in this table, I combined them into one category. The U.S. Census and the ASCP data also have a category for individuals claiming multiple ethnicities. That data from the U.S. Census and ASCP was excluded from Table 4 since it has no equivalent in the SJSU applicant pool data.

\section{Data Analysis}

Data was organized and aligned with the research questions. Quantitative data was used to address research questions one, two, and three. For research question four, I examined essays twice, coding each of them twice to generate a relatively stable list of codes. These codes were then organized using key concepts from the theoretical framework (The Social Cognitive Career Theory or SCCT): personal interests, selfefficacy, goals/actions, barriers, and support. These were chosen to help characterize the candidates' approach to the application process and how that approach intersected with the model.

\section{Findings and Discussion of Research Questions}

Statistical analysis was performed on each admission cycle separately. Considering the cycles separately was necessary because some applicants applied in multiple cycles. Analyzing them separately allowed the data to meet the requirement for independence in this model. However, it made the groups considered in RQ2 and 3 small (20-40 individuals) and limited their statistical power. 
Research Question 1. What characteristics (age, gender, ethnicity, academic performance) distinguish between applicants who are offered an interview to the program and those who are not?

Using a logistic regression model, I examined how each of these variables influenced admission to interview after a review of the paper application. Ethnicity not reported was correlated in a significant way to being offered an interview for one cycle, $(\mathrm{p}=0.02)$ Spring 2017. Degree from a university that is not a California State University or University of California campus was negatively correlated with being offered an interview in one cycle (Spring 2017, $\mathrm{p}=0.05$ ). Only GPA was significant $(\mathrm{p}>0.05$ ) for more than one cycle (Spring 2017, Fall 2017, Spring 2018).

Research Question 2. What characteristics (age, gender, ethnicity, academic performance, work experience) distinguish between applicants who are offered a placement after an interview and those who are not?

To answer this question, similarly to the RQ1 models, applicants were subset by the cycles they applied, and a logistic regression was fitted. This gave four logistic regression models, one for each of the four cycles. From the modeling of this data, there is no evidence that any of the variables considered correlate to whether candidates are offered placement.

Research Question 3. How do qualities selected for during the admissions process correlate to success on the board exams required for CLS licensure?

To examine this question, the grades in the prerequisite courses that correlated to sections on the ASCP exam were correlated with the score on that individual section of 
the exam. These included hematology, immunology, and medical microbiology. Only immunology had a statistically significant but quite small influence on the total score, explaining less than $10 \%$ of the variance in scores.

Research Question 4. What preparation did applicants make to qualify for admission?

I examined applicant essays and interviewed successful program graduates to evaluate candidate preparation of the application process. Coding for essays and the interviews was organized with the SCCT model in mind. This model, as previously referenced, is depicted in Figure 1.

The model suggests that personal interests and background (choice distal contextual affordances) lead to learning experiences that create an individual's self-efficacy expectations and outcome expectations. These, in turn, are thought to create interests that allow the formation of goals leading to actions to further the individual's path toward a career. In this model, one's network of contacts and personal circumstances (socioeconomic, caregiver responsibilities, experiences of discrimination in hiring) influence the translation of those interest and goals into actions. This is postulated as a recursive process that individuals use to explore their interests and refine the skills they imagine to be necessary for success in a given career. Selected quotations are used to illustrate how candidates described their experiences in alignment with this model, learning more about themselves and the profession as they gained experience through school and work. This is grouped as follows: First, I describe how personal interests, background inspire learning experiences. These experiences lead to expectations of self- 
efficacy. Candidates also describe the actions they took following this model to further refine and define their interest. Finally, I use candidate stories to show that the interview process itself provides candidates with experiences and information that clarify their interest in the CLS profession and in specific clinical sites.

\section{Personal Interests and Background Inspire Interest in Learning Experiences}

Applicants commonly structured their essays to call out directly how their background and personal qualities led to the learning experiences, interests, and actions that culminated in their application to the CLS program. Some candidates related early experiences that sparked an interest in science (which I refer to as "origin stories" below) and an appreciation for the laboratory in the context of health care work experience. Others spoke of how inspiring it was to see theory brought to life through work or personal experiences in health care (which I refer to as "inspiration through application"). Names used in these examples are pseudonyms.

\section{Origin stories contextualize the development of personal interests. A few} applicants mentioned that family members' experience in health care had influenced their own interest and journey towards a laboratory career. Stories with this feature are represented well by the following narrative offered by Sofia:

My grandmother was known as a curandera, a healer that brought her faith and superstitions to a tiny house in Los Angeles. I would watch her take care of the locals' mild aches and illnesses but never gave it much thought at the time, brushing her practices off as just something all grandmothers did. It was only when she was diagnosed with cancer and given two months to live that I found myself curious again.

I believe what makes me a strong candidate is that I have worked in both sides of the clinical setting from patient care to laboratory work. For example, I volunteered in Nicaragua by setting up a local clinic and working directly with 
patients. In that respect I did feel a bit like my grandmother as I listened to people's ailments and provided any immediate treatment I could.

Applicants also explained about how their interests had led to experiences in health care or to a particular interest in the clinical laboratory, as illustrated by Phuong's choice of volunteer work:

My involvement as a volunteer reaffirmed my passion for health care and opened me up to the field of clinical laboratory science. Since graduating in 2014, I have sought out experiences to help me prepare for a future career in the field.

Another candidate, Robert, expressed the evolution of his interests away from direct patient care to the testing areas of the laboratory as he was exposed to the significance of that work:

As an addition to the clinical lab, I bring my willingness to learn, my enthusiasm towards working as a team, and my strong work ethic. Having worked at (X) Hospital outside the laboratory, I've had the opportunity to see just how important timely and accurate results are, whether it is waiting on PT/INR results before taking a patient to surgery or just waiting on a pregnancy test result before a patient can get their X-rays.

Sofia, Phuong and Robert articulate the recursive nature of developing interest in a laboratory career; an interest in health care careers led to volunteering or working in a health care setting which introduced the individual to laboratory careers. They all then sought out additional experiences to refine their skills to prepare for the application process for CLS. What is striking about these examples is the hidden nature of laboratory work. It takes exposure to a specific set of experiences to appreciate the value and importance of laboratory testing and the nature of that work.

\section{Refining a general interest in science to an interest in CLS through application}

of theory. It was also common for candidates to express how exciting it was to see 
subjects they studied in school "come to life" as they experienced those subjects in the context of the laboratory setting, as Jian writes:

I remember learning about Zika virus in my medical microbiology class and a few weeks later at work I started to see more and more patients getting tested for it. This lab test was so new that doctors didn't even know how to order it in our system. Having the opportunity to learn and see this emerging disease affect people so close to home was an eye opening [sic] experience and made me realize the importance of laboratory medicine.

For some applicants, personal illness was what introduced them to the importance of the

laboratory profession and inspired them to learn more, as Tyrone recounts:

At the age of 21, I had started experiencing symptoms of what I would find out almost three years later were caused by an autoimmune disorder. During this lengthy diagnostic journey, I was determined to apply knowledge gained from my classes to not only understand the physiological mechanisms of my condition, but also the various diagnostic tests required to identify and monitor it. It was this specific life event that opened my eyes to just how indispensable clinical laboratory professionals are to patient care.

In these examples, as with the three in the previous section, there is a sense that the CLS profession and its impact on patient care had to be discovered through direct experience. Both Robert and Tyrone describe the personal impact laboratory work had and the interest it generated. The hypothetical becoming real before their eyes intrigued them and encouraged them to continue on the path to becoming a CLS.

\section{Self-efficacy Expectations: Soft Skills and Technical Skills}

Many of the candidates who received an invitation to interview had previous experience of some kind in a health care setting and related that experience back to specific skills they believed would be important in laboratory work. These skills that could be roughly grouped into three sets: soft skills, impacts on patient care, and technical skills. 
Soft skills. In an effort to underscore her value as a member of the laboratory team, Karina describes how her job in a clinical setting requires communication with other team members:

I frequently communicate with the Bacteriology CLSs on specimen lookups and processing samples that need to be screened within a short timeframe immediately after being processed. I am an invaluable asset to the clinical laboratory due to all of my aforementioned skills.

Carlos has a similar story to highlight different but complementary strengths.

My ability to stay on task has made me a dependable and versatile team player. Working in the different positions and departments has given me experience in the stages of laboratory testing: pre-analytical, analytical, and post-analytical.

These two examples illustrate how candidates chose to emphasize different aspects of their competency in the laboratory. They both focus on "soft skills" but in the first, the applicant's ability to "communicate" is called out in the context of a specific task. In the second quote, the applicant describes general skills (stay on task, dependable, versatile) and writes about specific phases of laboratory testing that show general understanding of how laboratorians think about the parts of the testing process. I interpreted this as displaying an appreciation for the culture of clinical laboratory work: distinguishing between these three phases is important because different rules and regulations govern who can perform the work in each phase. In California, for example, licensed personnel are the only individuals who can perform analytical phase work. A laboratory worker who is acting within their scope would need a firm understanding of these distinctions. In both of these examples, the candidates chose to showcase their understanding of the organization of responsibility within the laboratory and where they contributed directly to the testing process. 
Not all candidates chose to focus on the positive aspects of working in the laboratory. One applicant who was admitted to interview but ultimately not selected for placement wrote:

I understand that a CLS career can also seem repetitive, fast-paced, and stressful, but I possess the attributes necessary to thrive in such an environment.

While this might be interpreted as an expression of a positive self-efficacy belief, it does seem to cast laboratory work in a negative light, rather than a positive or inspiring one. It is tempting to speculate that if the candidate's approach to answering interview questions followed a similar theme (lab work is hard but I can deal with that) that they might have seemed negative and difficult co-workers.

Improving patient care. Some candidates included specific examples of how their work in health care had directly impacted either the quality of care provided to patients or the experience patients had while in the candidate's care. One candidate, Rianna, wrote about working with a reference lab to avoid having a patient come back for recollection of a sample:

One of the things that I noticed was the patients who didn't give enough volume for sputum samples, who were being denied specific tests because there was a minimum requirement of five milliliters. If that amount was not obtained, then the doctor would have to induce the patient. So, I proposed we add saline to the sputum already collected which could possibly suffice the original requirement. I assumed the saline would have no effect on the results, however, after discussing with the lead scientist from LabCorp, I was informed it would give the test a false negative because the sample would be too dilute. Although that was the case, the lead scientist determined that three milliliters of sputum would be enough. And although my original suggestion to add saline was rejected, it had resulted in the lead scientist's decision to lower the amount of sputum required from patients.

Another candidate, Norman, wrote more about his interaction with the patient in his work as a phlebotomist and how their work with a specific patient had a positive impact: 
The patient and her husband were both very apprehensive and asked if they could wait in our lobby until they received the results. Depending on a certain outcome, she would be sent directly to the emergency room. The patient was very distraught and the only way I knew how to help was to make sure that her labs were taken care of. I informed them when the courier came to pick up the sample, when the tube arrived in the lab and when it was being processed. This made me realize that I was a bridge between the patient and the lab.

Both of these examples show strong communication skills used to support good patient care experience. Where they differ is in their orientation. In the first case, Rianna was advocating for patients behinds the scenes, questioning established policy to prevent patients from needing to recollect (delaying care) and undergo an uncomfortable additional procedure. In the second example, Norman is in a patient facing role, addressing the anxiety an individual patient and their husband. In that case, he made laboratory procedure more transparent so that the patient felt cared for. Both Rianna and Norman recognized that they played a critical role in patient care and, I assume, included these examples in their essay to show that they had compassion for patients, a key value in health care. This aligns them with the culture of health care and the clinical laboratory. This strengthens their argument that they would make effective, productive members of the health care team.

Laboratory techniques. Experience with laboratory techniques was one of the common ways applicants showed investment and effort in becoming a good candidate for training. One notable difference between those who were offered positions and those who did not related to the types of experience they described and the detail they included in their descriptions. For example, Andrea writes about blood banking production skills useful in the clinical lab: 
Working at [my current employer] gave me my first real glimpse at what it would be like to work in a clinical lab. I would regularly handle and process clinical samples such as peripheral blood, bone marrow, cord blood, and apheresis packs.

I interpret Andrea's story to imply that her success in doing work that is critical to the production of products regularly used in the lab. She describes her role in the preanalytical component of testing and uses specific technical terminology to show the complexity of what she was doing. What she describes is working up to the limit of what is technically legal for an unlicensed person to do in California. Other candidates were less specific in their description of what they were doing in the lab or passive about their role, casting others as actors. In this example, technician Charlo describes his role in a passive way without details as to his responsibilities or actions as part of the laboratory:

I now work at a toxicology laboratory as a chemistry lab technician and I have the opportunity to observe the clinical lab scientists there every day.

Unlike the previous example, Charlo is not an actor or advocate. He references no specific skills or values driving his interest in the work.

In this example, candidate Kaitlyn describes a research background that parallels clinical work in that the same techniques are used in microbiology but in this case, applied to plant pathology:

I started working at [company $\mathrm{x}$ ], an agricultural biotech, soon after graduating [college]. I took an investigative approach to uncover bacterial and viral pathogens in seed samples, similar to what might be done in a clinical lab. These samples contained an unknown microbiological make-up, and through bacterial cell culture, reading plates, and running molecular assays such as PCR, I was able to screen seeds for these pathogens and quarantine them from distribution.

This story does describe specific techniques used in Kaitlyn's work, but they are not related to work with people. As is often the case with candidates with a background 
similar to Kaitlyn, she was interviewed but not offered an internship. I interpret this to mean that technical skills alone are not sufficient to persuade education coordinators to accept a student. They are more likely to accept candidates like Andrea, Rianna, and Norman, perhaps because they did a better job aligning their interests and skills with the values of health care.

\section{Barriers to Educational Experiences and Actions Leading to a CLS Career}

A small number of program applicants chose to call out specific barriers to entry into the program and explain how they navigated them. These represented both "choice distal" influences like emotional and financial struggles, experiencing a personal loss, and a lack of knowledge of the career during school. Applicants also navigated barriers related to "choice proximal" qualities like caregiving responsibilities, family status, a perceived preference on the part of clinical sites for "locals" and an understanding of the culture of applying for jobs in the U.S. Some examples are provided here.

The barrier of personal loss leading to academic struggle. Previously, several applicants indicated that a personal or family illness inspired their interest in the CLS profession. Candidate Tasha indicates that her father's death was a barrier to entry because of the emotional impact and its disruption of their academic work:

Shortly after starting (college) my biggest role model and hero, my dad, was diagnosed with cancer for the first time. It was devastating and I struggled a lot during this time as my family came to grips with the reality of my dad's illness. I entered a personal downward spiral and unfortunately, my academics suffered. After being put on academic probation at (my university), I took a year off and reassessed my views about college.

Tasha ultimately resolved her academic issues and described how her father's death two years later did not derail her in her studies. I assume that she told this story to show 
resilience and perseverance, but the in-depth description of this sequence of events occupied about a quarter of her essay. Tasha was ultimately not admitted to the program in any of the cycles studied, possibly because her poor academic performance lowered her rank and made it unlikely for her to place. It is also possible that she might have been more successful if her essay had focused more on her strengths and her skills, rather than the trauma of this event. It would also be interesting to know if, in her conversation with education coordinators, Tasha focused on her flaws and mistakes or talked about her strengths and interests.

Family responsibilities as a barrier. Applicant Jainam wrote of his responsibilities as a parent to three small children and how they slowed his progress through school, yet he still ends on an inspirational note:

My children, now 5, 6, and 7, watched me over the four years at (college) strive to maintain a balance between family-life, work, and school; yet more importantly they have seen me persevere. I feel that watching me go back to school has been rewarding for my kids and I hope one day they will realize from witnessing firsthand that with great struggle comes great reward.

This applicant threaded the theme of struggling to finish school and get prerequisite courses throughout their essay. Ultimately, they pitched that struggle as a positive good example, but this contrasted with other candidates who talked about how they hoped to inspire their family members, helping others by working in the lab. Jainam was not successful in gaining a placement in the cycles studied.

Another applicant indicated that he was limited in which program he could participate in because he was place bound due to of family responsibilities. Damian worked around this barrier by getting a job at a clinical affiliate associated with SJSU to increase his 
chance of being admitted to an online program with a local clinical affiliate. He told me in our interview:

I looked into what the requirements of [the SJSU program] were. It was, for the most part, online versus having to move... [I considered] the cost that was involved in that, my family dynamic and how that would be impacted....during my senior year [in college] is when I picked up a night shift position at [my future training site] to get my foot in the door, because that's how I perceived that that was the way to get into it.

This story differs from the previous two in that it describes specific actions Damian took to overcome barriers he saw preventing him from training. In his conversation with me, he expressed a positive outlook and gratitude at having obtained the job at his clinical site during his undergraduate years. This story reminds me more of those told by other successful applicants (Rianna, Norman) who focused on aligning themselves as closely as possible with clinical laboratory work.

\section{Understanding and navigating American interview conventions as a barrier. A}

repeat applicant, Chandra, explained in her interview with me how she remedied a lack of experience with the American style of interviewing using a local "one stop" employment center. These state-run centers (known generically as workforce investment boards) provide a connection to jobs, job training, and resume polishing / interview preparation.

The applicant writes about a coaching session to improve interview skills:

When I was answering, they told me, "This one, you're not giving the straight answer." Or, "This part, you're just elaborating more. You have to be very concise about it." Some of them, whichever I did good, they're like, "Oh, this is how you have answered, so you got the point."

This candidate was ultimately offered a placement after several applications cycles but credits her success to the coaching and mock interview provided at the "one stop." What 
is notable about her case is that she had more than five years of experience as a technician in a clinical lab, experience that ordinarily would have increased the chance of program admission. Despite strong academic performance and excellent experience, Chandra was offered a placement only after she learned to talk about these strengths in the interview in a culturally appropriate way.

The applicant essay provided many examples and stories describing the development of interest in science, CLS as a profession, and candidate self-efficacy expectations. Essays and interviews were used to describe some barriers to program entry, all following the SCCT model. In the next section, I use quotes from interviews with program graduates to explain how the interview process acts as a learning experience which, in turn, allows candidates to gain self-efficacy expectations as candidates and future CLS, evaluate their interest in CLS as a profession, and determine which clinical site will best meet their needs.

\section{The Program Interview: Mutual Evaluation and Information Gathering}

Applicants for the program engage in two types of interviews before admission. They are given the opportunity to visit clinical affiliates, which are usually group tours with multiple candidates (though a small minority of hospitals do engage one-on-one with candidates). There is also an interview on campus with education coordinators and SJSU CLS Program staff.

The interviews at the clinical affiliates emerged as a clarifying event as well as an evaluative one. In my interviews with program graduates for this research, I found that clinical sites that allowed for smaller groups and more personal interactions were more 
valuable to this effort. Candidates did attempt to show interest in all affiliates and had strategies for conveying their skills and commitment to the profession. They also appeared to gather information strategically during their interviews at the clinical sites and these experiences often seemed to reinforce their own ideas about whether this career path was the right one for them.

Showing the education coordinator you fit. Several applicants indicated in their interview with me that they made an effort to show their understanding of laboratory work because of previous work experience. Elisa told me:

When I went to the interviews and to the hospitals, I told them, "I worked with CLS, so already I know many things about the lab, about how it works, how the culture works, and everything." I was trying to convince them I'll be a good fit for their company.

Another candidate, Damian, managed his nervousness by reminding himself of how well he fit in as a "lab person":

I'm talking with my people. So it's not something scary. So, yeah, just talking about the profession and where we feel like we fit that, that fits in health care in general, how we've found our place doing that.

In both cases, Elisa and Damian made an effort to show the interviewers that they fit in with the lab culture and understood what would be expected of them when they became CLSs. This is an extension of the theme previously described above when candidates expressed their feelings of self-efficacy and used stories to convey how they had soft skills needed for lab work.

Making an effort to build rapport with the education coordinator. Graduates that I interviewed noticed a difference in the approach that education coordinators were taking to the interview process and adapted accordingly. Elisa also told me: 
If they made it clear what kind of person they were looking for, then I would try to make sure they saw me in that light.

Another candidate, Chris, made specific efforts to build rapport in the informal time he had with education coordinators.

...you got to your destination early, you had 10 minutes to spare and you started talking. And so that does help, they might ask about hobbies, what did you do? How was your drive and where you from. Those just kind of come up naturally and then what do you appreciate that you do that also that the person you're talking to also does. And then you just keep going from there.

Elisa also used non-verbal cues to try to build rapport and connect:

I definitely tried to smile. I wanted to come off as friendly and attentive. Definitely things like eye contact, I guess and listening attentively. I would do that, but that's how I am anyway....

The different strategies in these quotes all represent ways of building rapport with the education coordinator and are proposed as positively influencing a candidate's ability to express their qualification for a position. Huffcutt, Van Iddekinge, and Roth (2011) describe five factors that influence interviewee performance: interviewer-interviewee dynamics, interviewee state influences, supplemental preparation, interview design, and demographic / personal characteristics. Those strategies all support positive interviewerinterviewee dynamics and would be predicted to support a successful interview.

Evaluation of the clinical site by the candidate. Another candidate, Esther, also appreciated when the education coordinator acknowledged the applicant's effort and preparation while also indicating what they were looking for in a student. It indicated to this applicant what the clinical site selected for in its candidates and what it valued in employees: 
I really appreciated the type of education coordinator that says, "You've made this baseline cutoff. We know that you can do it technically. What we want to know is how you are as a worker and behaviorally and how you get along with people," because that just showed me that they cared more about the type of workplace environments that they created.

Chandra told me about how she looked for certain qualities in her training site that she valued and used them to evaluate the academic and clinical affiliate:

When I went to interviews, especially when I went to [my training site], I saw a lot of students were there. Also, it's very organized. Then, I decided, "Oh, this is the place I want to work. If I get into the programs, if they pick me, I want to choose this hospital."

...So I always asked about, what is your experience with training, and do you ... have you trained a lot of students? How often do they stay with your organization as opposed to go somewhere else? Because that to me says you create an environment that people want to stay in. So that was something that was important to me. And if they made it clear that they were looking for someone who would stick around and showed me specific aspects that they look for in order to create that environment, that made it more appealing to me....

Regarding the academic affiliate, she stated:

San José State, I like it because I went to [two other programs]. San José State is more organized, especially [the program coordinator]. When she was there, she helped us with all the paperwork.

Some clinical site visits allowed candidates to eliminate clinical sites because the clinical site did not show the values that the candidate was looking for. Carol explained it this way:

They just didn't have the type of environment where they felt like they wanted to get to know each individual, like they cared about each individual.

During the interviews, the CLS program and the clinical affiliates each signaled how they valued the applicant and this influenced that applicant's choice. 
Refining their approach and learning from others. As candidates like Esther toured the clinical sites, they learned from her own experiences and also from the applicants she was touring with:

...just asking questions in order to figure out what kind of training environment each place had, and then what questions they asked me to see what kind of candidate I was, gave me insights on what I should be asking the next person or what kinds of questions I could better prepare for the next interview in case I got asked.

Carol described a similar process:

...It was kind of, I think, a learning process as I went along. What were the right questions? Observing the people and how they work, would you like to work in this type of environment? Does it seem that your direct supervisor or boss possibly would have a great personality that you would mesh well with?

This harkens back to the SCCT model. Carol and Esther are both using the interview process as a learning experience, improving their interview self-efficacy expectations. The interview as a learning experience also leads them to have goals (as in, I would like to go to clinical site "X") and take action (ingratiating themselves with the education coordinator and building rapport as described above, asking questions) that help them navigate the placement process. 


\section{Chapter 5: Key Findings, Conclusions, Discussion, and Recommendations for Future Action}

This chapter summarizes key findings and offers conclusions alongside a discussion generated from the key findings. Recommendations for further study and implications for action are also presented.

This study achieved its objectives as an exploration of the impact of demographic factors, work history, and applicant preparation on their ability to successfully navigate the admissions process for the CLS program at SJSU. It also queried whether student performance in prerequisite coursework predicted their performance on their board exam at the end of the training program. This analysis was done using mixed methods with a correlational and descriptive approach. This study considered the admissions process from the perspective of the program, and from the perspective of the applicant, interrogating their perception of barriers within the process and exploring the strategies they used to overcome those barriers.

\section{Summary of Key Findings}

Research Question 1. What characteristics (age, gender, ethnicity, academic performance) distinguish between applicants who are offered an interview to the program and those who are not?

No statistically significant correlation was found between the demographic characteristics of the applicants and their probability of being admitted to interview for the program. This finding validated the fairness of the admissions process in that it seems not to have bias on the basis of race/ethnicity, age, and gender. The distribution of ethnicities in the SJSU applicant pool does not reflect the distribution in the laboratory 
workforce nationally, or in the U.S. or California general population. The distribution of genders was constrained to a binary choice by the data collected on the original application. Future iterations could yield a more nuanced spectrum in that category.

As seems warranted, academic performance as measured by GPA had a statistically significant association with admission to interview but contributed less than $10 \%$ to the probability of being offered and interview. This could be interpreted in a number of ways. It is possible that there is a "floor effect" at work. The GPA cut-off for the program creates a floor of 2.85 as the lowest GPA that can be admitted. It is possible that this filters out those candidates whose academic performance would exclude them from consideration. It is also possible that other factors not measured in this study are responsible for selection for interview including stories and experiences described in the personal statement and work experience.

Research Question 2. What characteristics (age, gender, ethnicity, academic performance, and work experience) distinguish between applicants who are offered a placement after an interview and those who are not?

None of the qualities mentioned above had a statistically significant impact on an applicant's chance of being offered a placement after interview. This validates that the process is free of measurable bias with respect to age, gender, and ethnicity. It was surprising that work experience did not impact the probability of placement after interview as those experiences can give candidates stories to tell about their understanding of what laboratory work requires and their alignment with the service mission of health care. But, here again, a confounding variable could be in place. It is 
possible that candidates were selected for interview in part because they had relevant work experiences and that was not a distinguishing factor in those who were ultimately offered a placement.

Research Question 3. How do qualities selected for during the admissions process correlate to success on the certification exams required for CLS licensure?

To evaluate this question, overall GPA was correlated with overall score on the ASCP certification exam and grades in prerequisite courses in immunology, hematology, and medical microbiology were compared to correlating sections of the exam. The only course that showed a correlation in grade in the prerequisite and performance on the board exam was immunology. The correlation was statistically significant but the effect was weak, explaining a small percent of the probability of achieving that score.

There are multiple possible interpretations of this data. It is possible that this is another example of a floor effect in the sense that most students who were admitted to the program had high grades $(\mathrm{B}+$ or higher) in their prerequisite courses and there was not enough variation in their performance to show an effect on their certification exam score. It is also possible that the program is acting as a leveling influence. In other words, it is possible that the program itself is effective in teaching students what they need to know to do well on the certification exam regardless of their preparation coming into the program. This is important to consider as, in my experience, education coordinators look closely at the grades in prerequisites courses and the mode in which they were taught (online vs. in person). This study shows that a student's previous preparation does not correlate with certification exam performance in a statistically significant way. 
Research Question 4. What preparation did students make to qualify for admission?

The preparation applicants undertook to qualify for the program fit well with the SCCT model, depicted earlier in Figure 1. Through their essays and my interview with program graduates, program applicants made an effort to show how their life experiences had led to learning experience that gave them the skills to be effective CLSs. Applicants described early life experiences with family members in health care careers, and personal characteristics like curiosity as inspiring them to acquire the education they needed to be a CLS. They also referred to work experiences as teaching them physical and cognitive skills needed in a science lab environment and "soft" skills they felt helped them show their ability to succeed as a CLS. Essays from applicants that were successful in placing in the program had more specific examples and stories showing that they had acquired the skills they claimed to have.

Another theme which emerged from the essays and interviews was that applicants evaluated the barriers they might encounter in approaching the application process. These included caretaking or family obligations, the availability of local training, and familiarity with the American style of interviewing and evaluating candidates. Successful candidates described how they had overcome those barriers so that they could succeed in achieving their goal to be a CLS.

Interviewing successful program graduates underscored the degree to which candidates continued to refine their ability to navigate the application process while in the interview stage of the application. Their experiences visiting clinical sites and observing other candidates allowed them to ask better or different questions about the clinical sites 
and to discern which work environments and co-workers would fit them best. As they proceeded through this process, it reaffirmed the candidates' interest in the program and refined their own understanding of where they would fit within the clinical laboratory. The interviews at clinical sites helped prepare candidates for the final interview at SJSU which was scored and directly impacted each candidate's rank and therefore their ability to place in a clinical site. The clinical site interviews provided critical information and training to candidates navigating the admissions process.

\section{Discussion and Conclusions}

The actions applicants took as they navigated this process fit well with the SCCT model and from that model I will speculate as to how it might be possible to have a more proportional balance in the distribution of gender and race/ethnicity in the applicant pool for the program. In general, this project did not show a clear path forward in terms of identifying a suite of success factors in approaching admissions to CLS training. It is possible to make statements about a lack of measurable bias in the admissions process, but my research shows that the population applying to the program is skewed with regard to gender and race / ethnicity and that this persists throughout the application process.

Based on these results, I concluded that the application process was not biased with respect to age, race / ethnicity, and gender. However, it is interesting to consider the reasons the applicant pool and the general population in California differ. Ideally, medical professionals are representative of the populations they serve; as research suggests, this is associated with better health outcomes and treatment (LaVeist \& Pierre, 2014). In California, we have some work to do in terms of increasing the number of 
Hispanic candidates in the pool to increase our chances of achieving those superior health outcomes. Since early life experiences are so inspiring, perhaps outreach efforts should be extended to younger children to give them a sense of what it is like to work in the laboratory. It might also be fruitful to partner with Hispanic organizations on college campuses to help raise awareness about this profession and opportunities to climb the laboratory career ladder. Finally, leveraging the career ladder concept might help Hispanic students in lower socioeconomic tiers stay the course academically and acquire the experiences they need to credibly argue for their place in the laboratory.

The gender balance is also skewed female in the national laboratory population, although the gender imbalance in the SJSU applicant population is not as extreme as it is nationally. Efforts to outreach to diverse genders promoting this career could help fix this modest imbalance. ASCP's continued use of binary gender categories is outdated. Perhaps attending to gender in a more inclusive way with more options would allow a more nuanced understanding of how people of different genders can be recruited into laboratory professions.

Addressing these demographic imbalances might be easier if the process that the SCCT model predicts young people will follow in discerning their future career is kept in mind. I briefly consider some of these factors in the sections that follow.

\section{Choice distal contextual affordances described by applicants. Early life} experiences helped develop the interest or awareness in laboratory science careers that were further refined during college and candidate's work experiences. Some candidates described general characteristics like curiosity, an affection for solving puzzles, and an 
enjoyment of hands-on work as key traits that helped them develop a general interest in science. Trang wrote:

[CLS work] reminded me of some of my favorite lab experiments from college, where we had to identify the given unknown chemical or bacteria. I had found those labs fun because it felt like I was cracking a puzzle and every test result got me closer to solving the mystery, so the ability to take part in solving the mystery of someone's illness and helping with his or her diagnosis and treatment intrigued me. It is work, I realized, I could find satisfaction in daily.

Some candidates described having a family member in health care or explained how either a family member's illness or their own illness helped them appreciate health care workers and the profound impact laboratory test results had on patient care. Given the types of experiences described by candidates of the program, giving young people more hands-on experiences to explore what it's like to work in a laboratory might inspire early interest in laboratory careers.

In later iterations through the model, applicants described how their work as an adult further developed or reinforced their specific interest in laboratory careers. Many applicants had extensive experience in biotechnology or research that was clinical lab adjacent, encouraging their interest in licensure because of their desire to advance to a higher level of responsibility within the laboratory. Others had worked as lab assistants in clinical laboratories and saw becoming a CLS as the next step in advancing up the laboratory career ladder. A lab assistant, Jamie, wrote:

Being at the forefront of the laboratory, I was able to obtain the patient's trust and ease any anxieties. I felt humbled serving patients with the best of my ability as they left the laboratory expressing gratitude from experiencing a painless blood draw. During breaks, I frequently migrated towards the back room of the laboratory where I observed the clinical laboratory scientists performing various tests. I became fascinated with the process of obtaining analytical data from 
patient samples. I became curious and wanted to know the science behind the clinical laboratory.

Candidates indicated that these experiences gave them confidence in their own physical, cognitive, and "soft" skills which led them to believe that they would succeed as a CLS. In our interview, Ester told me:

This may be interpreting wrong, but I felt like academically and having a background in various kinds of lab professions, that I would already have enough baseline experience to get through the door, and that it was more in some ways soft skills that made a difference....

Encouraging students to find work in health care or in a clinical laboratory seems the most straightforward approach to giving them rich experiences which might inspire an interest in laboratory careers and give them good stories to tell.

Learning experiences. Commonly, early experiences described by applicants led them to pursue science degrees that qualified them for application to the CLS program. Work experiences or internships that are in health care or the clinical laboratory would give them additional experience to help discern if a laboratory career is an attractive option. As applicant Rita wrote:

In the ten years of working alongside clinical laboratory scientists, there are three things that I have learned and observed that are valuable in the profession: knowledge, staying focused, and compassion. These are traits that I possess and know that I can apply to my life-long career as a CLS.

It might also make sense to encourage more undergraduates to take clinical laboratory oriented prerequisite courses so that they have required coursework complete as part of their degree and have an opportunity to gain a greater appreciation for the field.

The interview process served as a final learning process, assisting candidates in further refining their preferences for particular locations and work conditions. Education 
coordinators can structure interviews in a way that assist candidates in discerning their place in the profession.

Self-efficacy and outcome expectations. Candidates most frequently expressed a sense of self efficacy in their hands on laboratory skills. This manifested as stories about specific techniques or methods they mastered in their school and workplace. More successful candidates often described specific experiences they had working in the clinical lab as lab assistants. In addition to specific lab techniques, laboratory skills spoke of having an eye for detail, troubleshooting, and good time management. Encouraging undergraduates to take more laboratory courses might increase their sense of self-efficacy with regard to laboratory skills. It might also be helpful to help students improve their interviewing skills since that is such a critical part of the admissions process for these programs.

"Soft skills" were another area which many successful candidates claimed to be strong. They wrote about their ability to be a good team player, their ability to communicate well, and their ability to connect with patients. Specific stories about patient interactions appeared in many of the essays written by candidates that were admitted for training. Health care and clinical lab adjacent experiences would help students and applicants develop a sense of what the needed skills are and of compassion and caring as a critical value for health care workers.

Candidates chose specific experiences for themselves because they felt their skills aligned well with their chosen role. Some explained their choice of occupation before applying to the program as a deliberate attempt to get closer to the clinical laboratory to 
have experience in a clinical setting. Others explained how research and biotechnology work had helped them develop skills and discern a fruitful path for themselves toward a laboratory career that would be meaningful. The expected outcome from this work was both to understand the clinical lab better but also to demonstrate effective laboratory skills and abilities.

Goals and actions. A candidate's journey to consideration for CLS training usually followed several cycles through the SCCT model as they refined their interests and skills through additional education and work. Applicants described a progression of goals and actions in their pursuit of a CLS career. All had pursued a science degree to qualify for the program, but the majority of applicants had taken addition courses to meet the CLS prerequisite requirements. Usually, this had been accomplished while the applicant was working in a lab related occupation but occasionally, the opposite occurred. Some candidates changed their occupation after they had become aware of the CLS program and had started taking classes. A minority of candidates went so far as to seek out employment at a clinical training site with the SJSU program in an effort to ingratiate and align themselves with a clinical training affiliate.

Barriers modulating goals and actions. The barriers that candidates experienced in getting trained to be CLSs varied. Almost all candidates had to take additional coursework after their bachelor's degree because they had not incorporated the required prerequisite courses in their major. Some discussed the influence of family responsibilities and how that delayed training or limited their ability to move to participate in training. Damian, for example, was place bound and knew he had only one 
local clinical affiliate to choose from. Other applicants expressed that the interview process seemed to constitute a barrier to getting all the information they needed to choose the right clinical site for training because they did not get a chance to speak with management and staff. Carol noted:

I should have tried to get a little bit more of a one-on-one interaction between some of the lab directors or one of the CLSs who worked for their labs. Because who knows, maybe I might've... Obviously, I trained in (my clinical affiliate), but maybe there were some other sites that I could have been interested in if I had more interaction with them

How applicants chose to address those barriers was critical. In Damian's case, he took a different job so that he could be a more competitive applicant:

It just seemed like your guys' program was the perfect fit because it could be done remotely. Then, yeah, I would need to go and work at another hospital. So during my senior year at (college) is when I picked up a night shift position at (the local clinical affiliate) to get my foot in the door, because that's how I perceived that that was the way to get into it. This per diem night shift position was a way to get in, let the lab people could get to know you because they were actively hiring all of their students.

This fits with the SCCT model in that choice proximal contextual affordances like contacts through a career network will influence a person's ability to get the skills and experience they need to qualify for a career. Other successful applicants highlighted how unexpectedly becoming a parent, or gaps in their educational journey helped them focus on the CLS career. Perhaps advisors and career counselors could work with applicants to help them frame their experiences positively and to mitigate barriers to program entry.

\section{Recommendations}

The object of this project was to identify success factors that contributed to an applicant's ability to gain admission to a CLS training program. The SCCT model 
suggests three points on the path to the development of career interest that help an applicant develop an interest in the field and acquire the skills and values needed to perform well. In this section, I briefly revisit each of these points in the model and then suggest how each helps students obtain the experiences they need to be successful CLS applicants.

The first point of potential influence is in the "choice distal contextual affordances" consisting of three major components; background, socialization, and support for the candidate. The applicant's background needs to include exposure to role models in the field and exposure to the tasks involved in the career. This helps socialize the applicant to the habits and values unique to health care. Emotional and financial support for the candidate is also important; its absence can be a barrier to program entry or can constrain the applicant's choices.

The second point of potential influence is self-efficacy expectations developed through applicant experience related to the field. Successful applicants had specific experiences in work or school that they used to show they had the technical skills and "soft" skills needed to succeed in the CLS field. This should include hands on science experiences and occupational experiences that are age appropriate as detailed in the tables below. Multiple authors support the connection between self-efficacy and career choice (Gore \& Leuwerke, 2000; Lent, Brown, Nota, \& Soresi, 2003; Lindley, 2005).

Finally, applicants need to manage their "choice proximal contextual affordances." To the extent possible, applicants need to build networks and connections with individuals in the field who can help them find work or training opportunities. Those who 
encounter barriers in their journey to acceptance to CLS training need to approach those barriers strategically and tell a positive story about their ability to mitigate or overcome those barriers. This approach could be used with children and adults, as detailed in Tables $5,6,7$, and 8 .

Table 5

Recommendations for Children 13 and Younger

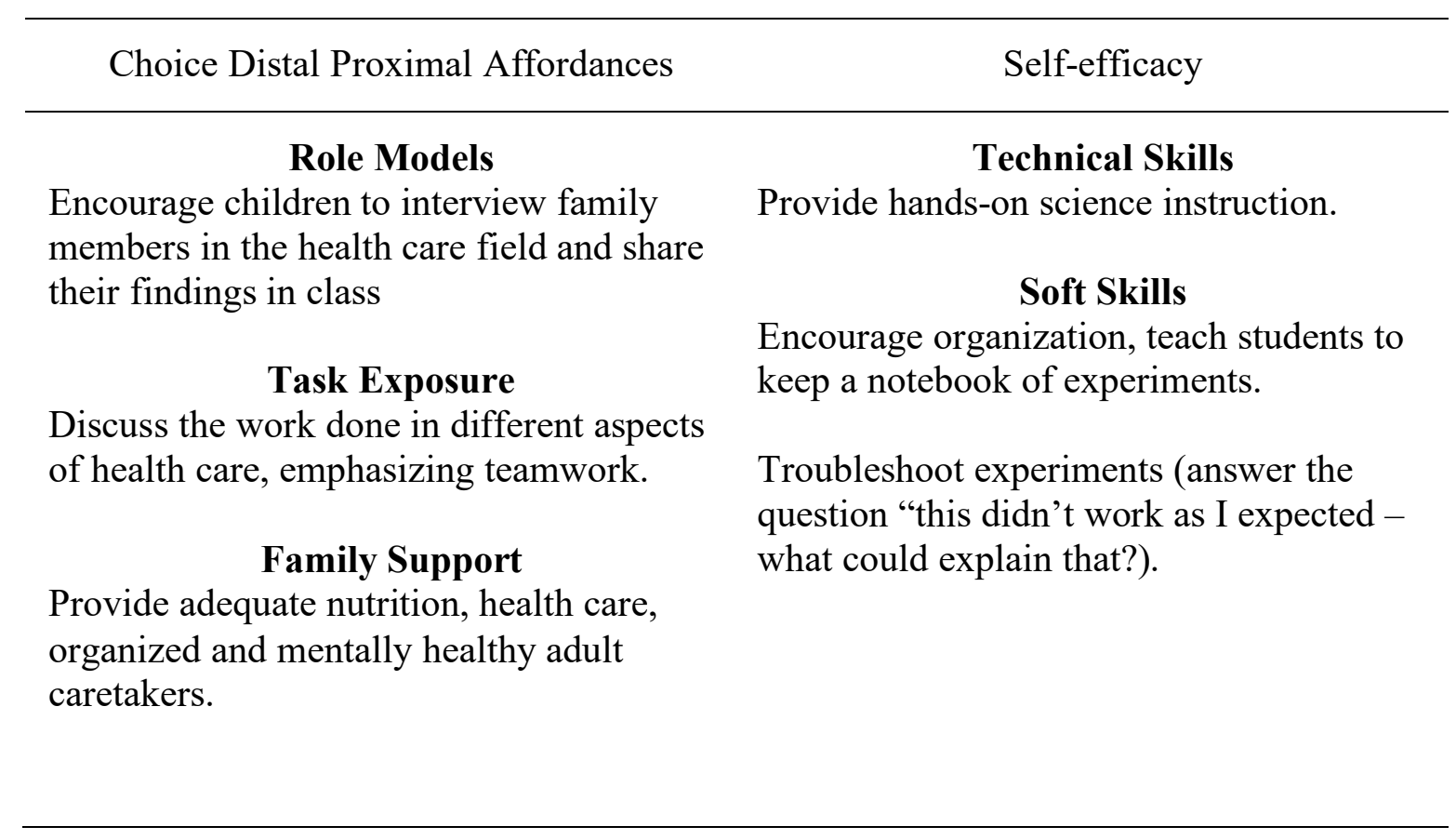


Table 6

Recommendations for High School Students

\begin{tabular}{|c|c|}
\hline Choice Distal Proximal Affordances & Self-efficacy \\
\hline Role Models & Technical Skills \\
\hline $\begin{array}{l}\text { Create_student_clubs that support career } \\
\text { exploration in the health sciences. }\end{array}$ & $\begin{array}{l}\text { Provide inquiry-based science experiments } \\
\text { designed to develop: }\end{array}$ \\
\hline $\begin{array}{l}\text { Offer high school career days that include } \\
\text { CLS professionals presenting about their } \\
\text { work }\end{array}$ & $\begin{array}{l}\text { - Pipetting skills } \\
\text { - Microscope skills } \\
\text { - Sterile technique }\end{array}$ \\
\hline $\begin{array}{l}\text { Task Exposure } \\
\text { Increase media exposure to medical } \\
\text { stories (documentary or fictional). }\end{array}$ & $\begin{array}{l}\text { Soft Skills } \\
\text { Require an organized notebook / record } \\
\text { keeping during science lessons. }\end{array}$ \\
\hline $\begin{array}{l}\text { Encourage students to get a part time job } \\
\text { in a field that requires basic medical } \\
\text { training (lifeguarding, recreation) or } \\
\text { volunteer work in a clinical setting. }\end{array}$ & $\begin{array}{l}\text { Teach troubleshooting - exposure to the } \\
\text { concept of positive and negative controls } \\
\text { and their use in evaluating experimental } \\
\text { results. }\end{array}$ \\
\hline $\begin{array}{l}\text { Family Support } \\
\qquad \begin{array}{l}\text { Provide adequate nutrition, health care, } \\
\text { organized and mentally healthy adult } \\
\text { caretakers. }\end{array}\end{array}$ & $\begin{array}{l}\text { Create group projects - Organizing } \\
\text { individuals to work together to achieve a } \\
\text { goal. }\end{array}$ \\
\hline
\end{tabular}


Table 7

Recommendations for College Students

\begin{tabular}{|c|c|}
\hline Choice Distal Proximal Affordances & Self-efficacy \\
\hline Role Models & Technical Skills \\
\hline $\begin{array}{l}\text { Offer coursework, clubs, that introduce } \\
\text { students to a variety of different health care } \\
\text { careers. }\end{array}$ & $\begin{array}{l}\text { Take courses which emphasize specific } \\
\text { techniques: } \\
\text { - Pipetting skills } \\
\text { - Microscope skills }\end{array}$ \\
\hline $\begin{array}{l}\text { Offer seminars or other education for } \\
\text { faculty advisors informing them as to the } \\
\text { most effective way students can approach } \\
\text { preparation for laboratory careers. }\end{array}$ & $\begin{array}{l}\text { - Sterile technique } \\
\text { Complete coursework in immunology, } \\
\text { hematology, medical microbiology with } \\
\text { labs. }\end{array}$ \\
\hline Task Exposure & Soft Skills \\
\hline $\begin{array}{l}\text { Engage in laboratory work in courses } \\
\text { integrating examples from the clinical } \\
\text { laboratory (case studies, application of } \\
\text { techniques to clinical problems). }\end{array}$ & $\begin{array}{l}\text { Practice writing about clinical } \\
\text { experiences and connecting them to a } \\
\text { personal sense of mission. }\end{array}$ \\
\hline $\begin{array}{l}\text { Obtain any of the following; part-time } \\
\text { jobs, internships, or volunteer work in a } \\
\text { clinical setting, as close to the laboratory } \\
\text { as possible. } \\
\text { Economic Support } \\
\text { Offer financial aid, scholarships, or loan } \\
\text { forgiveness for students pursuing careers in } \\
\text { the clinical laboratory }\end{array}$ & $\begin{array}{l}\text { Practice interviewing skills to prepare for } \\
\text { program applications. } \\
\text { Obtain research experience to practice } \\
\text { formulating a question and learning } \\
\text { different skills needed to answer the } \\
\text { question }\end{array}$ \\
\hline
\end{tabular}


Table 8

Recommendations for Post-Baccalaureate Students

Choice Distal Proximal Affordances

\section{Role Models}

Increase outreach by professional societies to connect with laboratory professions, which could be through career-oriented talks at professional meetings or by working with local workforce investment boards to connect with individuals changing careers.

Offer seminars or other education for career advisors informing them as to the most effective way students can approach preparation for laboratory careers.

\section{Task Exposure}

Work in a laboratory field, preferably in a clinical laboratory.

\section{Economic Support}

Create a free or low cost bridge program to help students get the classes they need to qualify for clinical laboratory training.

Provide financial aid, scholarships, or loan forgiveness for students pursuing careers in the clinical laboratory.

\section{Self-efficacy}

\section{Technical Skills}

Courses which emphasize specific techniques:

- Pipetting skills

- Microscope skills

- Sterile technique

Coursework in immunology, hematology, medical microbiology with labs.

\section{Soft Skills}

Practice writing about clinical experiences and connecting them to a personal sense of mission.

Practice interviewing skills to prepare for program applications.

Work with / Troubleshoot instruments at work to teach this important skill for the laboratory.

Participate in quality control activities to become familiar with quality assurance and total quality management principles.

For children 13 and younger, I would support quality science and math instruction in elementary school and middle school. I would encourage clinical laboratory professional societies like the American Society for Clinical Laboratory Science (ASCLS) and the American Society for Clinical Pathology (ASCP) to collaborate with teachers to create 
lesson plans that fit with the state curriculum, which educators could then use to introduce the idea that there are exciting and interesting things to learn about the human body, emphasizing to students that there is a whole range of professions that allow people to explore that interest, not just the professions of doctor or nurse. I would also encourage students to ask their family members about the work that they do and have them present their findings to their classmates so that everyone has a chance to hear about the work their family members are doing.

For high school students, I would also try to create lessons incorporating clinical laboratory topics that harmonize with the state mandated curriculum. For example, if a high school has a forensic science class, perhaps part of it could be devoted to techniques that are also used in the clinical laboratory with some discussion about how those methods are applied in both settings. I would also encourage ambassadors from professional societies to visit school career days and talk about the profession, similar to the ASCP ambassador program, encouraging students to plan on taking the prerequisite classes they need as part of their college education.

In college, I would educate faculty advisors and academic advisors about the steps students need to take to most efficiently approach preparing for laboratory careers. This would include advising early and often to make sure students incorporate prerequisite courses into their course of study for their major. Colleges should offer career-oriented courses to students like the SJSU Biology 44 course which allows students to meet professionals working in various biological fields. This course is taught primarily by working professionals who come in on rotation to talk about their work. I would also 
encourage students to take jobs in health care and in a clinical laboratory if possible. If they can be persuaded to be certified in phlebotomy, that would be very helpful as it would introduce students to the first step in the laboratory testing process. I would also encourage students to work with the career center on campus to practice interviewing so that they have a well-written resume and are proficient in their interviewing skills

For postbaccalaureate students, I would make advising available to them so that they can chart the shortest path to becoming qualified to apply for clinical training. If they have not done so already, I would encourage them to get a job or volunteer experience in a health care setting as close to the laboratory as possible. If utilizing a "career ladder" approach would help them financially, I would encourage these students to work their way progressively through the low skill / unlicensed laboratory careers (phlebotomy, specimen processing, laboratory assistants) to the more highly skilled (medical laboratory technician) on their way to becoming a CLS. I would encourage them to leverage the career center at their alma mater or a local workforce development center to improve their ability to express their experiences in their personal statement and through interviews.

Finally, I would leverage applicant's previous experiences and training in health care. I would encourage foreign students with a medical background to have their transcripts evaluated so that they can chart the shortest path possible to the degree or credentials they need to qualify for CLS training. I would encourage the Veteran's Administration (VA) to help service members navigate the complex state licensure process. This would help veterans leverage the training they receive in the military and avoid repeating their 
training. VA hospitals could also help with bridge programs to give veterans the opportunity to train to meet state requirements. Both of these groups would also benefit from help with resume writing and interviewing skills which could be provided by state workforce investment boards.

\section{Conclusion}

This project provided a detailed look at the admissions process to the CLS program at SJSU. It examined the process from the perspective of the program, evaluating the process for bias, and showed that the academic credentials required for interview are sufficient to select candidates that should perform well on the ASCP certification exam. Applicants and program graduates spoke eloquently about the importance of hands-on experiences both to encourage interest in the profession and to provide the rich narrative that allowed individuals to make a strong case for their admission to training. Finally, the findings underscored the importance of framing. Successful applicants did encounter barriers on their journey toward training but focused on pragmatically addressing and overcoming those barriers. With these principles in mind, students and their advisors have a path to follow, starting in elementary school and continuing through the postbaccalaureate years, that should produce well-qualified candidates for admission into a CLS training program. 


\section{References}

Allied Health Professions Overview. (2018). https://explorehealthcareers.org/field/alliedhealth-professions/

Anderson, D. D., \& Shore, W. J. (2008). Ethical issues and concerns associated with mentoring undergraduate students. Ethics \& Behavior, 18(1), 1-25. doi:10.1080/10508420701519577

Association of Schools Advancing Health Professions. (2020). What is allied health? https://www.asahp.org/what-is

Baldwin, A., \& Agho, A. O. (2003). Student recruitment in allied health educational programs: The importance of initial source of contact. Journal of Allied Health, $32(2), 65-70$.

Bandura, A. (1986). Social foundations of thought and action: A social cognitive theory. Englewood Cliffs, N.J.: Prentice Hall.

Bandura, A. (1991). Human agency: The rhetoric and the reality. American Psychologist, 46(2), 157-162.

Barfield, J. P, Folio, M. R., Lam, E. T. C., Zhang, J. J. (2011). Development of a scale to determine enrollment barriers into allied health programs. Measurement in Physical Education and Exercise Science, 15(1), 47-66. doi:10.1080/1091367x.2011.544970

Briscoe, V. J., \& Anema, M. G. (1999). The relationship of academic variables as predictors of success on the National Council Licensure Examination for Registered Nurses (NCLEX-RN) in a selected associate degree program. ABNF journal, 10(4), 80 .

Carpio, B., O'Mara, L., \& Hezekiah, J. (1996). Predictors of success on the Canadian Nurses Association Testing Service (CNATS) examination. The Canadian Journal of Nursing Research, 28(4), 115-123.

Cassidy, T., \& Wright, L. (2008). Graduate employment status and health: A longitudinal analysis of the transition from student. Social Psychology of Education, 11(2), 181191. doi:10.1007/s11218-007-9043-X

Chun Tie, Y., Birks, M., \& Francis, K. (2019). Grounded theory research: A design framework for novice researchers. SAGE Open Medicine, 7. https://doi.org/10.1177/2050312118822927

Corbin, J., \& Strauss, A. (2014). Basics of qualitative research: Techniques and procedures for developing grounded theory (4th ed.). SAGE publications. 
Creswell, J. W. (2005). Educational research: planning, conducting, and evaluating quantitative and qualitative research (2nd ed.). Upper Saddle River, N.J.: Prentice Hall.

Creswell, J. W., \& Poth, C. N. (2018). Qualitative inquiry and research design: Choosing among five approaches (4th ed.). Los Angeles: SAGE Publications.

Danek, J., Borrayo E. (2012). Urban universities: Developing a health workforce that meets community needs [Report]. Coalition of Urban Serving Universities and The Association of Public and Land Grant Universities. https://communitywealth.org/content/urban-universities-developing-health-workforce-meetscommunity-needs

Fuse, A. (2018). Needs of students seeking careers in communication sciences and disorders and barriers to their success. Journal of Communication Disorders, 72, 4053.

Fussell, E. F., \& Furstenberg, F. F., Jr. (2005). The transition to adulthood during the twentieth century: Race, nativity and gender. In R. A. Settersten Jr., F. F. Furstenberg Jr., \& R. G. Rumbaut (Eds.), On the frontier of adulthood: Theory, research, and public policy (pp. 29-75). Chicago, IL: University of Chicago Press.

Gabard, D. L. (2007). Increasing minority representation in the health care professions. Journal of Allied Health, 36(3), 165-175.

Gabard, D. L., Porzio, R., Oxford, T., \& Braun, R. (1997). Admission interviews: Questions of utility and cost in masters of physical therapy programs in the United States. Physiotherapy Research International, 2(3), 135-149.

Garcia, E., Kundu, I., \& Fong, K. (2020). The American Society for Clinical Pathology's 2019 survey of medical laboratories in the United States. American Journal of Clinical Pathology, 1-25. doi:10.1093/ajcp/aqaa197

Glazer, G., \& Bankston, K. (2014). Holistic admissions in the health professions: Findings from a national survey [Report]. Urban Universities for HEALTH. https://www.aplu.org/library/holistic-admissions-in-the-health-professions/File

Goode, T. D., Dunne, M. C., \& Bronheim, S. (2006). The evidence base for cultural and linguistic competency in health care [Report]. The Commonwealth Fund. https://www.commonwealthfund.org/publications/fund-reports/2006/oct/evidencebase-cultural-and-linguistic-competency-health-care

Goodyear, N., \& Lampe, M. F. (2004). Standardized test scores as an admission requirement. Clinical Laboratory Science, 17(1). 
Gore, P. A., Jr., \& Leuwerke, W. C. (2000). Predicting occupational considerations: A comparison of self-efficacy beliefs, outcome expectations, and person-environment congruence. Journal of Career Assessment, 8(3), 237-250.

Hammarstrom, A. J., \& Janlert, U. (2002). Early unemployment can contribute to adult health problems: Results from a longitudinal study of school leavers. Journal of Epidemiology and Community Health, 56, 624-630. DOI: 10.1136/jech.56.8.624

Harrelson, G. L., Gallaspy, J. B., Knight, H. V., \& Leaver-Dunn, D. (1997). Predictors of success on the NATABOC certification examination. Journal of Athletic Training, $32(4), 323$.

Higgins, C. A., \& Judge, T. A. (2004). The effect of applicant influence tactics on recruiter perceptions of fit and hiring recommendations: A field study. Journal of Applied Psychology, 89(4), 622.

Higher Education Research Institute at UCLA. (2014). The American freshman: National norms fall 2014 [Research brief]. http://www.heri.ucla.edu/briefs/TheAmericanFreshman2014-Brief.pdf

Huffcutt, A. I., Van Iddekinge, C. H., \& Roth, P. L. (2011). Understanding applicant behavior in employment interviews: A theoretical model of interviewee performance. Human Resource Management Review, 21(4), 353-367.

Ivankova, N. V., Creswell, J. W., \& Stick, S. L. (2006). Using mixed-methods sequential explanatory design: From theory to practice. Field methods, 18(1), 3-20.

Jewell, D. V., \& Riddle, D. L. (2005). Method for predicting a student's risk for probation in a professional program in allied health. Journal of Allied Health, 34(1), 17-23.

Kaddoura, M. A., Flint, E. P., Van Dyke, O., Yang, Q., \& Chiang, L.-C. (2017). Academic and demographic predictors of NCLEX-RN pass rates in first- and seconddegree accelerated BSN programs. Journal of Professional Nursing, 33(3), 229-240.

Kenny, C. J. (2010). Meta-analysis of entrance standards for undergraduate nursing and selected allied health programs (Doctoral dissertation, Kent State University). Retrieved from http://rave.ohiolink.edu/etdc/view?acc_num=kent1284583045

Kudlas, M. J. (2006). Effects of radiography program admissions practices on student retention. Journal of Allied Health, 35(3), 162-168.

Kume, J., Reddin, V., \& Horbacewicz, J. (2018). Predictors of physical therapy academic and NPTE licensure performance. Health Professions Education, 5(3), 185-193.

La Veist, T. A., Pierre, G. (2014). Integrating the 3Ds - social determinants, health 
disparities, and health-care workforce diversity. Public Health Reports, 129(Supplement 2), 6.

Lee, J. O., Jones, T. M., Yoon, Y., Hackman, D. A., Yoo, J. P., \& Kosterman, R. (2019). Young adult unemployment and later depression and anxiety: Does childhood neighborhood matter? Journal of Youth and Adolescence, 48(1), 30-42. doi:10.1007/s10964-018- 0957-8

Lent, R. W., Brown, S. D., \& Hackett, G. (1994). Toward a unifying social cognitive theory of career and academic interest, choice, and performance. Journal of Vocational Behavior, 45(1), 79-122.

Lent, R. W., Brown, S. D., \& Hackett, G. (2000). Contextual supports and barriers to career choice: A social cognitive analysis. Journal of Counseling Psychology, 47(1), 36.

Lent, R. W., Brown, S. D., Nota, L., \& Soresi, S. (2003). Testing social cognitive interest and choice hypotheses across Holland types in Italian high school students. Journal of Vocational Behavior, 62(1), 101-118.

Lent, R. W., Hackett, G., \& Brown, S. D. (1999). A social cognitive view of school-to-work transition. The Career Development Quarterly, 47(4), 297-311.

Lindley, L. D. (2005). Perceived barriers to career development in the context of social cognitive career theory. Journal of Career Assessment, 13(3), 271-287.

McDonald, S., Erickson, L. D., Johnson, M. K., \& Elder, G. H. (2007). Informal mentoring and young adult employment. Social Science Research, 36(4), 1328-1347. doi:10.1016/j.ssresearch.2007.01.008

Merriam, S. B. (1998). Qualitative Research and Case Study Applications in Education. Revised and Expanded from" Case Study Research in Education. ": ERIC.

O'Banion, T. (1994). An academic advising model. NACADA Journal, 29(1), 83-89

Payton, O. D. (1997). A meta-analysis of the literature on admissions criteria as predictions of academic performance in physical therapy education in the United States and Canada: 1983 through 1994. Physiotherapy Canada, 49(2), 97-102.

Platt, L. S., Turocy, P. S., \& McGlumphy, B. E. (2001). Preadmission criteria as predictors of academic success in entry-level athletic training and other allied health educational programs. Journal of Athletic Training, 36(2), 141.

Salvatori, P. (2001). Reliability and validity of admissions tools used to select students for the health professions. Advances in Health Sciences Education, 6(2), 159-175. 
Sanderson, T. R. (2014). Relating admissions criteria to dental hygiene student retention. Journal of Allied Health, 43(4), 235-240.

Solberg, B. L. (2015). Critical thinking as a predictor of certification exam performance in medical laboratory science. Clinical Laboratory Science, 28(2), 76.

Taylor, M. S. (1985). The roles of occupational knowledge and vocational self-concept crystallization in students' school-to-work transition. Journal of Counseling Psychology, 32(4), 539-550.

United States Bureau of Labor Statistics. (2018). Unemployment rate 2.7 percent for people ages 45-54, 8.3 percent for 16 to 24 in October 2018.

https://www.bls.gov/opub/ted/2018/unemployment-rate-2-point-7-percent-for-peopleages-45-to-54-8-point-3-percent-for-ages-16-to-24-in-october-2018.htm

United States Census Bureau. (2019). QuickFacts: California. https://www.census.gov/quickfacts/fact/table/CA/PST045219

Ward, S. T., Downey, M. C., Thompson, A. L., \& Collins, M. A. (2010). Predictors of success in dental hygiene education: A follow-up study. American Dental Hygienists' Association, 84(1), 24-28.

Wolkowitz, A. A., \& Kelley, J. A. (2010). Academic predictors of success in a nursing program. Journal of Nursing Education, 49(9), 498-503.

Yin, T., \& Burger, C. (2003). Predictors of NCLEX-RN success of associate degree nursing graduates. Nurse Educator, 28(5), 232-236. 


\section{Appendix A: Interview Questions and Consent Form}

Questions for the semi-structures interview:

1. I praised the organization.

2. I complimented the interviewer or the organization.

3. I discussed non-job-related topics about which the recruiter and I share similar opinions.

4. I discussed interests I shared in common with the recruiter.

5. I found out what kind of person the organization was seeking and explained how I fit in.

6. I indicated my interest in the position and the company.

7. I indicated my enthusiasm for working for this organization.

8. I smiled a lot or used other friendly non-verbal behaviors.

9. I maintained eye contact with the interviewer. 


\section{Consent Document:}

\section{REQUEST FOR YOUR PARTICIPATION IN RESEARCH}

TITLE OF THE STUDY: Success factors leading to admission to the San Jose

State University Clinical Laboratory Scientist Training Program

\section{NAME OF THE RESEARCHER}

Mara Williams, MT(ASCP) M.S.

Graduate Student - San Jose State University

Under the direction of:

Grinell Smith, Ph.D

Faculty Advisor - San Jose State University

PURPOSE: This study is being conducted to identify success factors in admission to the SJSU CLS Training Program. This interview will explore what actions you took to prepare for the interview and your opinions about what you thought made you successful. At the end of the study, results will be reported as part of my dissertation and given to the CLS Program Director for program improvement.

PROCEDURES: Data for this study will be collected through a semi-structured interview that will take place in person, via phone or through zoom. Audio will be recorded but edited before transcription to remove any personally identifying information from the recording. Transcription will be performed by the company Rev. The interview will last 15-20 minutes.

POTENTIAL RISKS: There are no known risks anticipated with participating in this interview. If the participant becomes uncomfortable or emotionally distressed during the interview or would prefer to not answer a question they are free to skip questions or discontinue the interview as they prefer.

POTENTIAL BENEFITS: This research will describe those qualities which are linked to successfully gaining admission into the SJSU CLS Training program. This could make it easier for future applicants to apply to the program and get accepted. It will also potentially help the CLS program identify factors that correlate better performance in the program.

COMPENSATION: No compensation will be provided.

CONFIDENTIALITY: Personally identifying information will not be collected as part of this interview process. If it is revealed as part of the interview, it will 
be edited out before transcription. Participants will be referred to by a pseudonym when the data are reported. 


\section{PARTICIPANT RIGHTS:}

Your participation in this study is completely voluntary. You can refuse to participate in the entire study or any part of the study without any negative effect on your relations with San Jose State University or [name any other participating institutions]. You also have the right to skip any question you do not wish to answer. This consent form is not a contract. It is a written explanation of what will happen during the study if you decide to participate. You will not waive any rights if you choose not to participate, and there is no penalty for stopping your participation in the study.

\section{QUESTIONS OR PROBLEMS}

You are encouraged to ask questions at any time during this study.

- For further information about the study, please contact Mara Williams at 408-768-[xxxx] or mara.williams@sjsu.edu

- Complaints about the research may be presented to the director of the Educational Doctorate Program, Dr. Bradley Porfilio, 408-924-3566, bradley.porfilio@sjsu.edu

- For questions about participants' rights or if you feel you have been harmed in any way by your participation in this study, please contact Dr. Pamela Stacks, Associate Vice President of the Office of Research, San Jose State University, at 408-924-2479.

You may keep a copy of this document for your records. 


\section{Appendix B: Details of the Statistical Analysis}

The study population consists of 486 applicants from four application cycles: Fall 2017 ( $\mathrm{n}=136)$, Spring 2017 ( $\mathrm{n}=117)$, Fall $2018(\mathrm{n}=125)$, and Spring 2018 $(\mathrm{n}=108)$. The following information regarding the applicants was extracted:

- $\quad$ cycle - the year and term for which the applicant applied.

- note - training site/alternate/not interviewed. This information should be consistent with variables interview and placement below.

- interview - whether the applicant was invited to an interview (1) or not (0).

- placement - whether the applicant was offered admission (1) or not (0). Those who did not get an interview should automatically have a value of 0 for this variable. Those who got admission must have been invited to an interview.

- Identification (id) - a long decimal number that uniquely identifies each applicant. ID remains the same when the applicant rejected in an earlier cycle re-applied.

- GPA - grade point average on a 0-4 scale of each applicant.

- degree - the institution where an applicant earned his/her bachelor's degree.

- age - how old the applicant is, calculated from his/her birth date to $12 / 01 / 2016,7 / 1 / 2017,12 / 1 / 2017,7 / 1 / 2018$.

- gender - gender of the applicant.

- ethnicity - ethnicity of the applicant.

- BBNK, UA, CHEM, HEMA, IMMU, MICR - scores earned by the applicants in each test of the board exam. Only those who passed the board exam have these entries non-empty. No missing scores were found.

- total - total score of the applicant in the board exam. Only those who passed the board exam have this entry non-empty.

- $\quad$ status - whether the applicant passed the board exam. Only those who passed the board exam have this entry non-empty. When this entry is non-empty, BBNK, UA, CHEM, HEMA, IMMU, MICR, and total are non-empty as well.

- immuno, heme, med_micro, biochem, physics - grade point average on 
a $0-4$ scale of the prerequisite courses to apply for the program; those are immunology, hematology, medical microbiology, biochemistry, and physics.

- immuno_onsite, heme_onsite, med_micro_onsite, biochem_onsite, physics_onsite - whether the applicant took the prerequisite courses onsite or online.

- hospital_intern, hospital_lab, medical_exp, clinical_lab, biotech_lab, research, volunteer, customer_service, teaching, military - quantifies work experience of the applicant in various categories. The number of months of experience was calculated for each category. When the number of months was not provided, applicants were assumed to have a year (12 months) of experience. Only 167 applicants who were invited to an interview had some forms of experience that could be evaluated based on their resume. No resume was available for the remaining candidates.

To facilitate later analyses, some of the variables above were processed as follows:

- interview - coded "yes" if the applicant was invited to an interview; "no" otherwise. There are no NA entries.

- $\quad$ placement - coded "yes" if the applicant was offered admission; "no" otherwise. There are no NA entries.

- degree - institutions were categorized into three groups: CSU, UC, and other universities. Other universities include Californian schools that are not part of the CSU or UC system, non-Californian schools within the U.S., and foreign schools.

- age - rounded to whole numbers.

- gender - coded $\mathrm{M}$ for male, $\mathrm{F}$ for female, and not given for NA.

- ethnicity - replaced NA by not given. There are three applicants that identified themselves as American Indian/Alaskan Native; coded as Other instead.

- immuno_onsite, heme_onsite, med_micro_onsite, biochem_onsite, physics_onsite - replaced NA by not_given. If the applicant took the course onsite, coded as "yes." If the applicant took the course online, coded as "no."

- hospital_intern, hospital_lab, medical_exp, clinical_lab, biotech_lab, 
research, volunteer, customer_service, teaching, military - Of 187

applicants who were offered an interview, we dropped 20 applicants who have no work data at all, and for the remaining 167 applicants we replaced NA by 0 .

Apart from these, we also added a repeater variable (column), to keep track of applicants who appear more than once in the spreadsheet. Note that an applicant that did not appear more than once in this spreadsheet may have applied in even earlier cycles, but we did not have the information to verify that. It is also

possible that an applicant that appeared more than once in this spreadsheet may have applied in even earlier cycles. 
RQ\#1: What characteristics (age, gender, ethnicity, academic performance) distinguish between applicants who are offered an interview to the program and those who are not?

To answer this question, applicants were subset by the cycles they applied, and a logistic regression was fitted. Thus, we have 4 separate logistic regression models. The response variable was interview, and the predictors (independent variables) were GPA, degree, age, gender, and ethnicity. For missing ages and GPA, mean imputation was used for each cycle.

$\underline{\text { Results }}$

Spring 2017

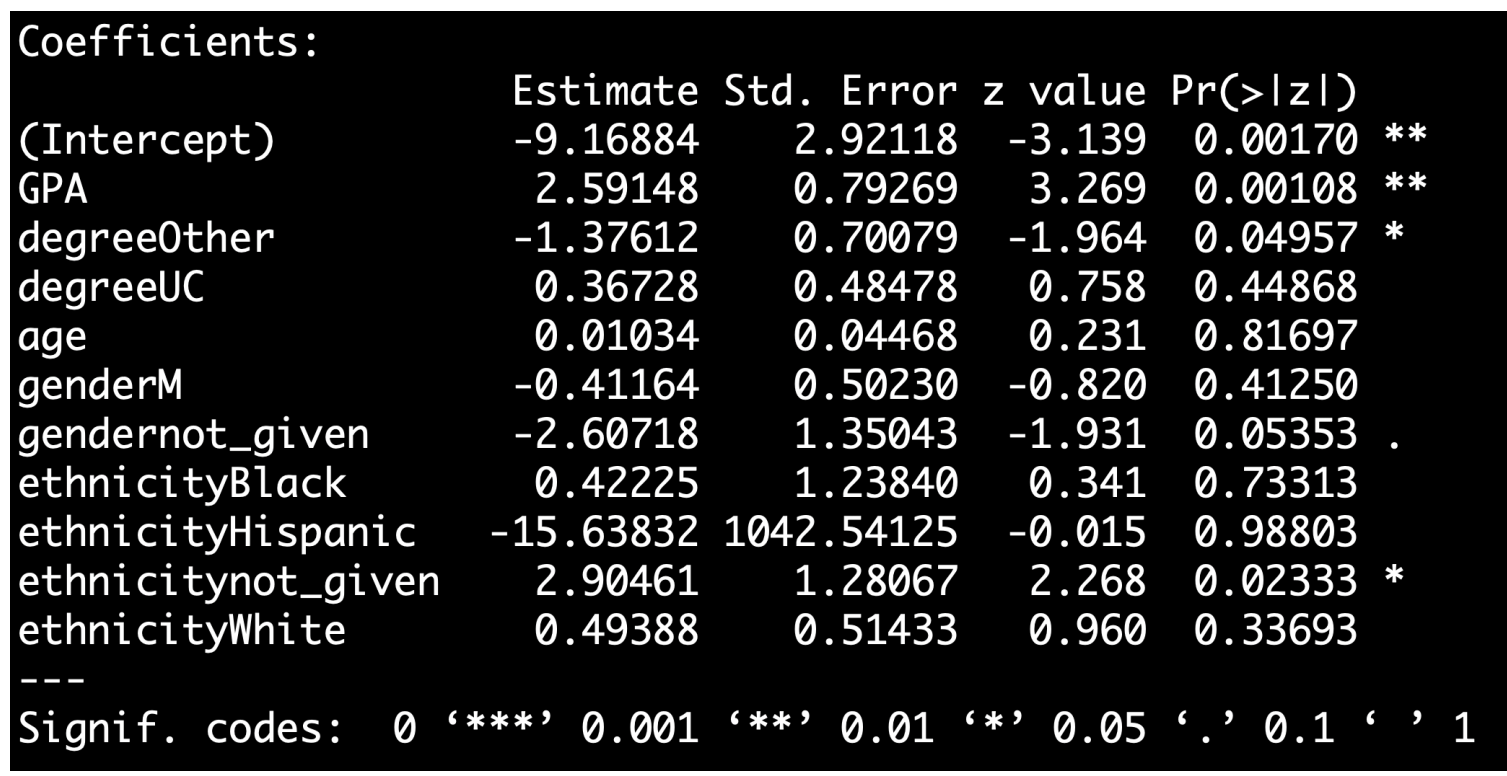




\begin{tabular}{|c|c|c|c|c|c|}
\hline \multicolumn{6}{|l|}{ Coefficients: } \\
\hline (Intercept) & $-17,76515$ & 3.63563 & -4.886 & $1.03 e-06$ & $* * *$ \\
\hline GPA & 5.00712 & 0.96726 & 5.177 & $.26 e-07$ & $* * *$ \\
\hline degree0ther & -1.39843 & 0.80025 & -1.747 & 0.0806 & \\
\hline degreeUC & -0.81528 & 0.49606 & -1.643 & 0.1003 & \\
\hline age & 0.03702 & 0.04686 & 0.790 & 0.4295 & \\
\hline genderM & 0.21534 & 0.50325 & 0.428 & 0.6687 & \\
\hline gendernot_given & 14.78105 & 1455.39767 & 0.010 & 0.9919 & \\
\hline ethnicityBlack & -1.37048 & 1.38024 & -0.993 & 0.3207 & \\
\hline ethnicityHispanic & 0.16173 & 0.78116 & 0.207 & 0.8360 & \\
\hline ethnicitynot_given & -14.30877 & 1455.39762 & -0.010 & 0.9922 & \\
\hline ethnicityWhite & 0.94600 & 0.56389 & 1.678 & 0.0934 & - \\
\hline Signif. codes: & $* 0$ & $\partial 1$ & $=0.05$ & ‘' & , 1 \\
\hline
\end{tabular}

Spring 2018

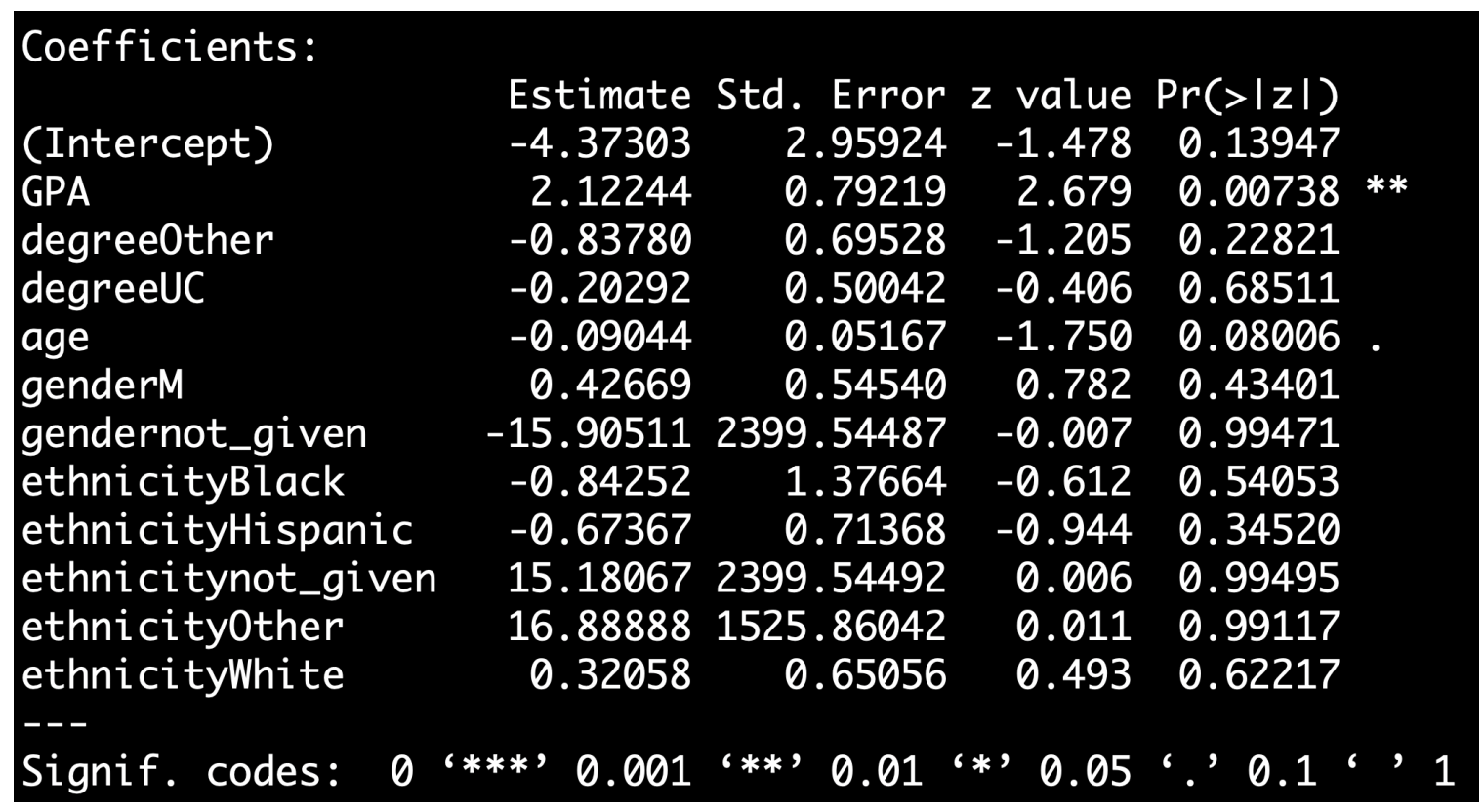


Fall 2018

\begin{tabular}{|c|c|c|c|c|c|}
\hline \multicolumn{6}{|l|}{ Coefficients: } \\
\hline (Intercept) & -4.00207 & 2.57559 & -1.554 & 0.1202 & \\
\hline GPA & 1.20118 & 0.70572 & 1.702 & 0.0887 & \\
\hline degree0ther & 0.07490 & 0.59256 & 0.126 & 0.8994 & \\
\hline degreeUC & -0.09274 & 0.46937 & -0.198 & 0.8434 & \\
\hline age & -0.01158 & 0.03911 & -0.296 & 0.7672 & \\
\hline genderM & -0.77606 & 0.44902 & -1.728 & 0.0839 & \\
\hline gendernot_given & 0.49268 & 1.36323 & 0.361 & 0.7178 & \\
\hline ethnicityBlack & 0.86353 & 1.46532 & 0.589 & 0.5557 & \\
\hline ethnicityHispanic & 1.22166 & 0.65232 & 1.873 & 0.0611 & \\
\hline ethnicitynot_given & -1.69874 & 1.43819 & -1.181 & 0.2375 & \\
\hline ethnicity0ther & 16.60013 & 1455.39762 & 0.011 & 0.9909 & \\
\hline nicitywhite & 16.04215 & 1455.39758 & 0.011 & 0.9912 & \\
\hline nicityWhite & 0.84726 & 0.52511 & 1.613 & 0.1066 & \\
\hline gnif. c & 01 & , & $a$ & ‘ 0.1 & , 1 \\
\hline
\end{tabular}

GPA was significant at 0.05 for all cycles except Fall 2018 where it was significant at 0.1 . Ethnicity not given was significant for three cycles: at 0.05 for Spring 2017 and at 0.1 for Fall 2017 and Fall 2018. Degree was significant for two cycles: at 0.05 or Spring 2017 and at 0.1 for Fall 2017. 
RQ 2: What characteristics (age, gender, ethnicity, academic performance, work experience) distinguish between applicants who are offered a placement after an interview and those who are not?

To answer this question, similarly to the "interview" models, applicants were subset by the cycles they applied, and a logistic regression was fitted. This gave four logistic regression models, one for each of the four cycles. The response variable was placement, and the predictors (independent variables) were GPA and all the ten work experience variables (hospital_intern, hospital_lab, medical_exp, clinical_lab, biotech lab, research, volunteer, customer service, teaching and military).

$\underline{\text { Results }}$

Spring 2017

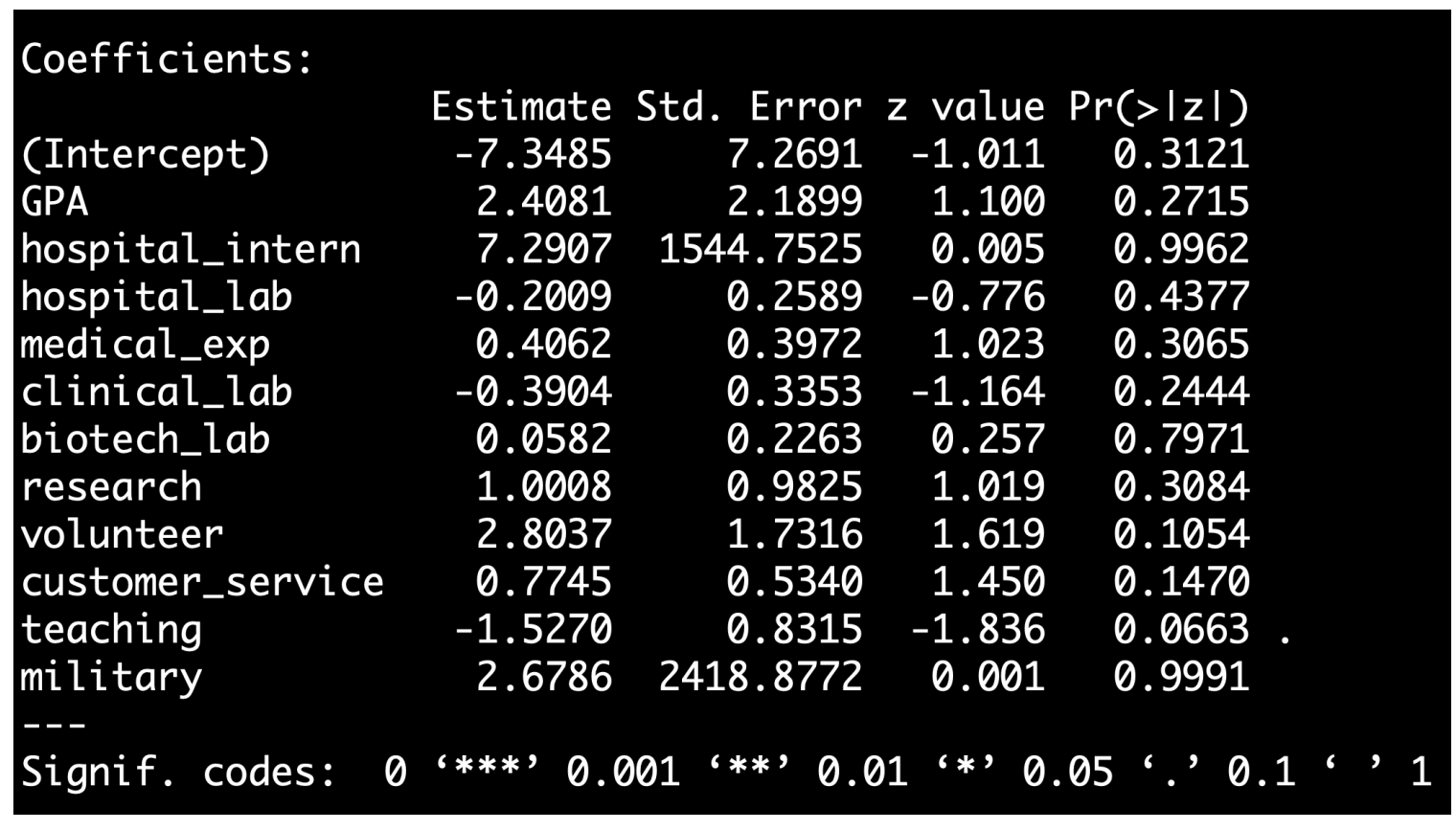




\begin{tabular}{lrrrr} 
Coefficients: & \multicolumn{5}{c}{} \\
& Estimate & Std. Error & value & $\operatorname{Pr}(>|z|)$ \\
(Intercept) & -5.4559 & 7.6623 & -0.712 & 0.476 \\
GPA & 1.1997 & 2.1489 & 0.558 & 0.577 \\
hospital_intern & 15.2968 & 2925.8002 & 0.005 & 0.996 \\
hospital_lab & 2.3750 & 2.1050 & 1.128 & 0.259 \\
medical_exp & 1.3270 & 1.0469 & 1.267 & 0.205 \\
clinical_lab & 0.9963 & 0.7275 & 1.369 & 0.171 \\
biotech_lab & 0.3753 & 0.3489 & 1.076 & 0.282 \\
research & 0.3795 & 0.6716 & 0.565 & 0.572 \\
volunteer & 0.4898 & 0.6766 & 0.724 & 0.469 \\
customer_service & 0.4905 & 0.3380 & 1.451 & 0.147 \\
teaching & 0.6282 & 1.3624 & 0.461 & 0.645 \\
military & 6.1309 & 1698.1708 & 0.004 & 0.997
\end{tabular}

Spring 2018

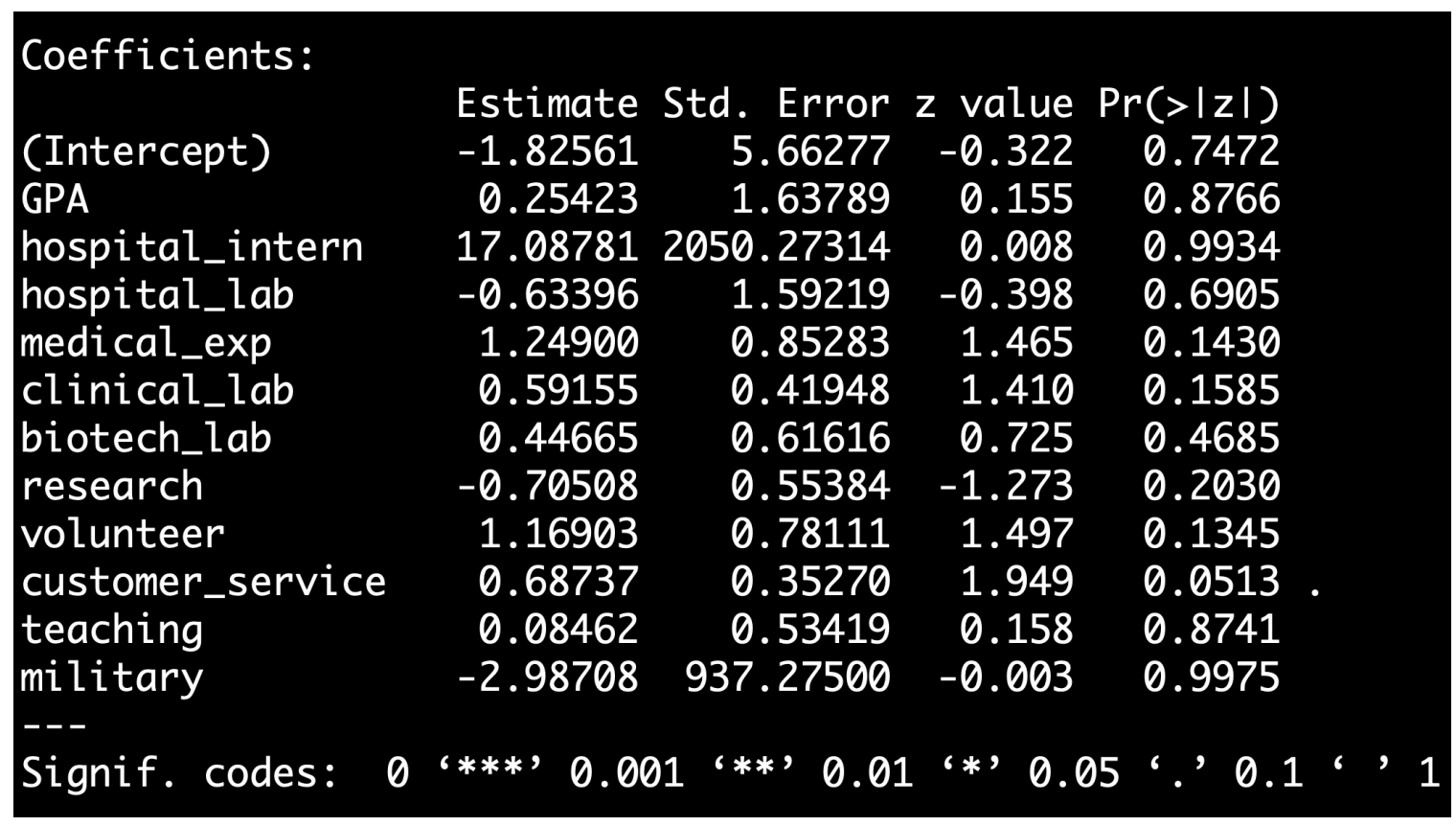




\begin{tabular}{lrrrr} 
Coefficients: & \multicolumn{5}{c}{} \\
& Estimate & Std. Error & z value & $\operatorname{Pr}(>|z|)$ \\
(Intercept) & 3.98060 & 4.37182 & 0.911 & 0.363 \\
GPA & -0.85039 & 1.28806 & -0.660 & 0.509 \\
hospital_intern & 8.13513 & 1439.72770 & 0.006 & 0.995 \\
hospital_lab & 0.10903 & 0.48255 & 0.226 & 0.821 \\
medical_exp & -0.02369 & 0.23221 & -0.102 & 0.919 \\
clinical_lab & -0.35890 & 0.54389 & -0.660 & 0.509 \\
biotech_lab & -0.33033 & 0.23353 & -1.415 & 0.157 \\
research & -0.30565 & 0.25827 & -1.183 & 0.237 \\
volunteer & 0.56448 & 1.33064 & 0.424 & 0.671 \\
customer_service & 0.31569 & 0.50637 & 0.623 & 0.533 \\
teaching & -0.44547 & 0.36410 & -1.223 & 0.221 \\
military & -2.23554 & 299.94311 & -0.007 & 0.994
\end{tabular}

None of the predictor variables were significant for all four cycles at 0.1 . Teaching was significant at 0.1 for the Spring 2017 cycle and customer service was significant at 0.1 for the Spring 2018 cycle. GPA was not significant in any cycle at 0.1 . From the modeling of this data, there is no evidence that GPA predicts whether or not an interviewed applicant gets a placement. There is also no consistent evidence between cycles that any of the work experience variables predicts placement success. 
RQ 3: How do qualities selected for during the admissions process correlate to success on the American Society for Clinical Pathology (ASCP) certification exam required for CLS licensure?

Is a student's grade in a particular subject (Hematology, Microbiology, and Immunology) a good predictor of the score in the same subject in the CLS exam after going through the program?

To answer this question, multiple linear regression models were fit for each of the three individual subjects using the CLS exam individual subject score as the response variable. The incoming grade in the subject and the application cycle (Spring 2017, Fall 2017, Spring 2018 and Fall 2018) were used as the two predictor variables.

$\underline{\text { Results }}$

Hematology

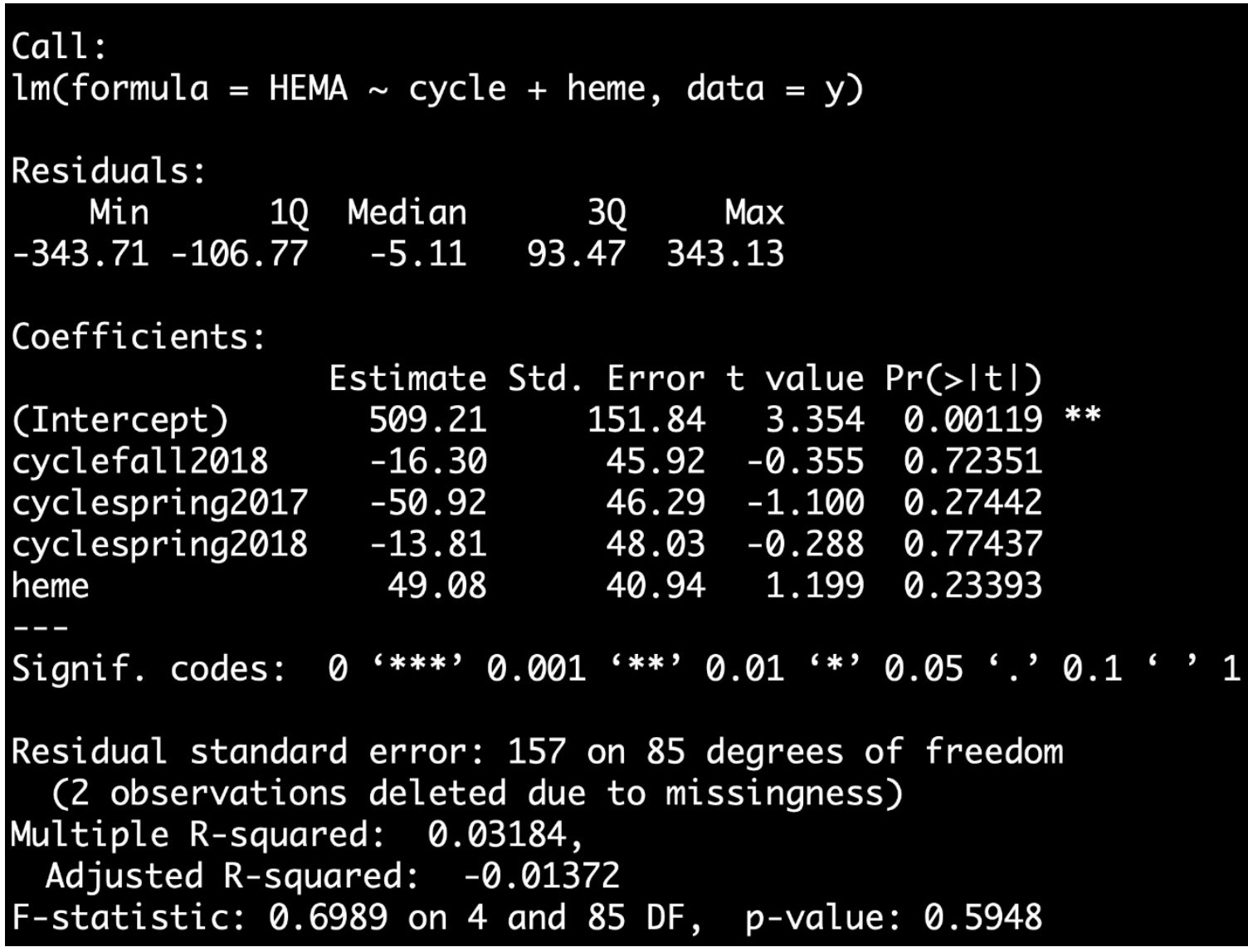

Neither cycle nor incoming GPA were significant. 
Microbiology

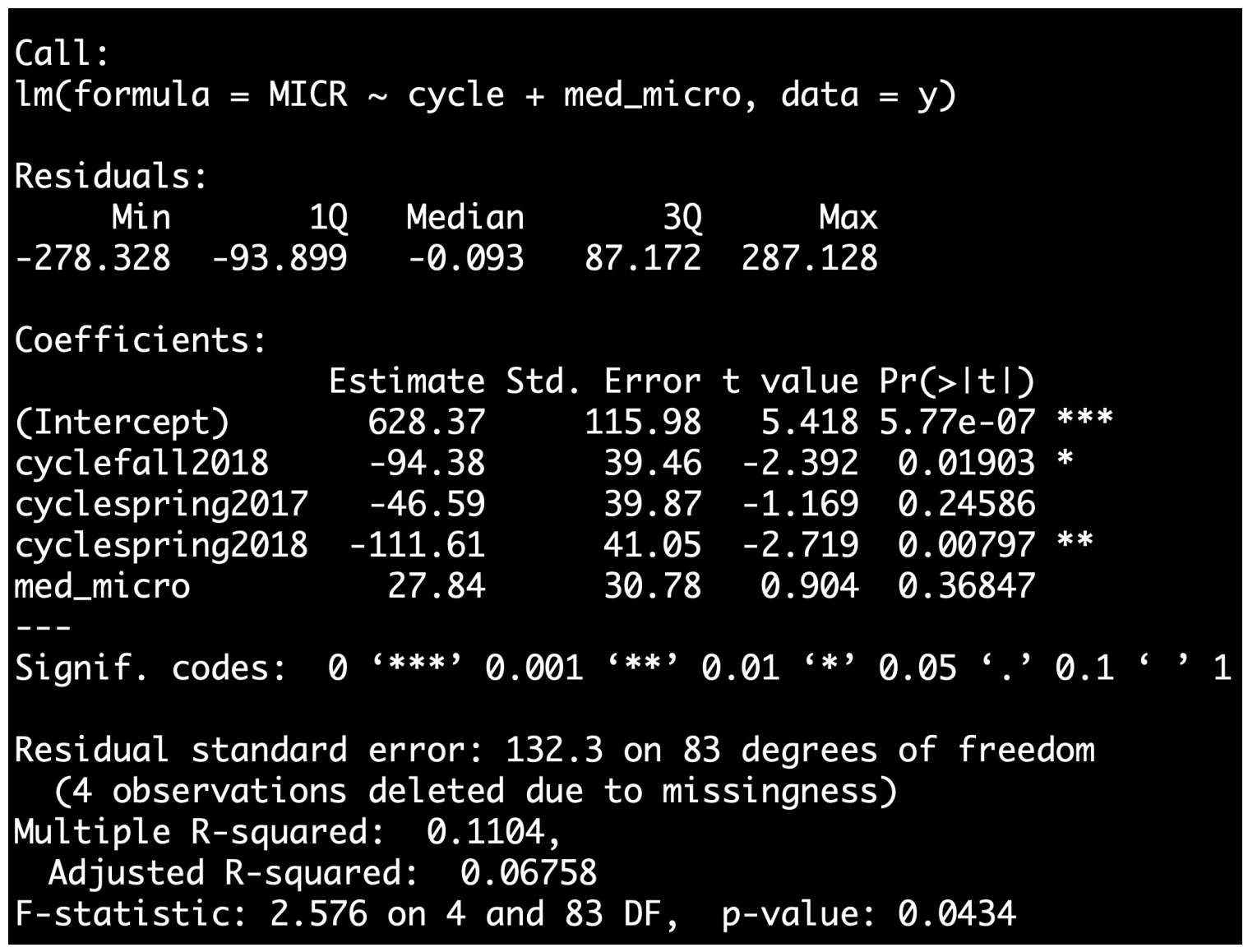

Incoming grade in a particular subject is not significant. Cycle significant at 0.01 . However, adjusted R-squared only $\sim 7 \%$, so cycle explains $7 \%$ of the variation in CLS microbiology exam score. 


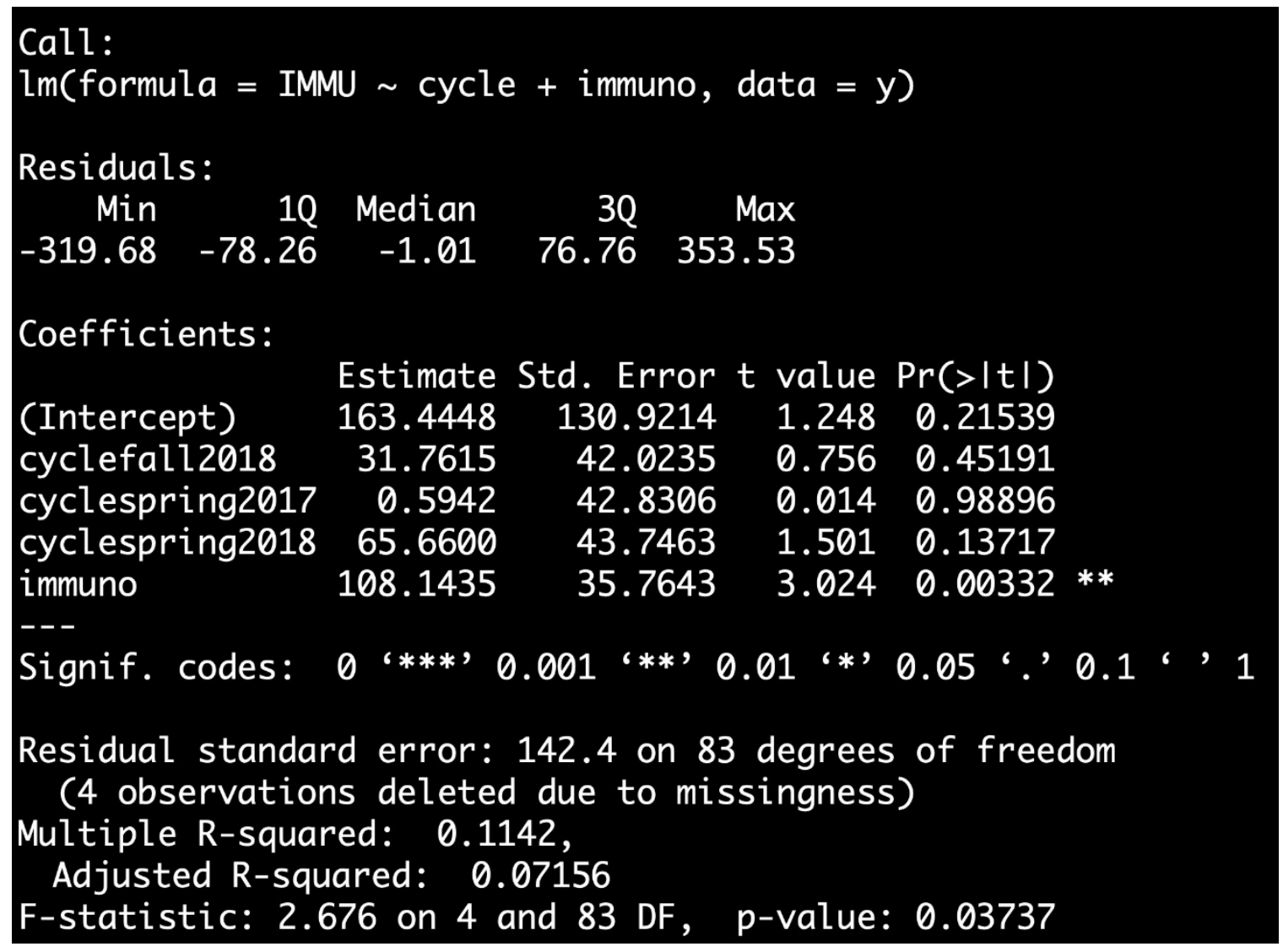

Cycle not significant. Incoming grade in immunology significant at 0.01 . However, adjusted R-squared only $\sim 7 \%$, so incoming grade in immunology explains $7 \%$ of the variation in CLS immunology exam score. 